Aus der Klinik für Nephrologie und Rheumatologie

(Prof. Dr. G. A. Müller)

der Medizinischen Fakultät der Universität Göttingen

\title{
BKV-Infektion bei nierentransplantierten \\ Patienten - eine retrospektive Analyse \\ vor und nach Etablierung eines \\ Screeningverfahrens
}

\author{
INAUGURAL-DISSERTATION \\ zur Erlangung des Doktorgrades \\ der Medizinischen Fakultät der \\ Georg-August-Universität zu Göttingen
}

vorgelegt von

Sofia Schmelev

aus

Barnaul, Russland

Göttingen 2020 
Dekan:

\section{Betreuungsausschuss}

Betreuer:

Ko-Betreuer:

\section{Prüfungskommission}

Referent/in:

Ko-Referent/in:

Drittreferent/in:

Datum der mündlichen Prüfung: 18.02.2021
Prof. Dr. O. Gross

Priv.-Doz. Dr. T. Lorf

Prof. Dr. O. Gross

Priv.-Doz. Dr. T. Lorf 
Hiermit erkläre ich, die Dissertation mit dem Titel "BKVInfektion bei nierentransplantierten Patienten - eine retrospektive Analyse vor und nach Etablierung eines Screeningverfahrens" eigenständig angefertigt und keine anderen als die von mir angegebenen Quellen und Hilfsmittel verwendet zu haben.

Göttingen, den ..............

(Unterschrift) 


\section{Inhaltsverzeichnis}

Abbildungsverzeichnis ....................................................................................... III

Tabellenverzeichnis ......................................................................................... III

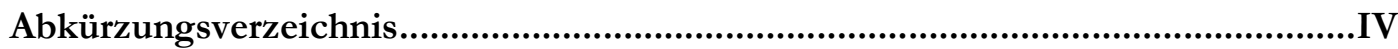

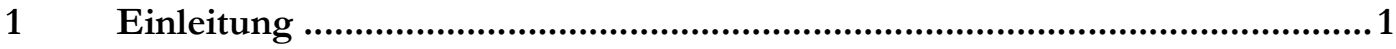

1.1 Das BK-Virus: Biologie, Genetik und pathogene Mechanismen ...............................................2

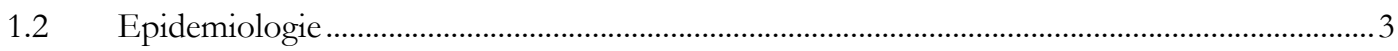

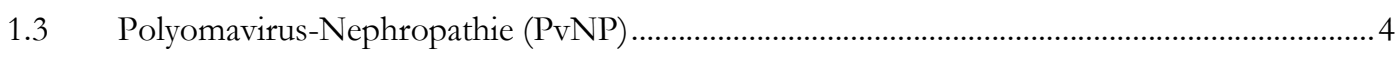

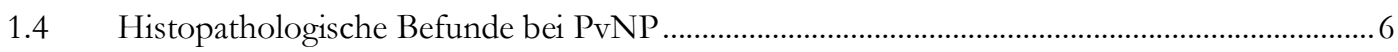

1.5 Risikofaktoren für die Entwicklung einer PvNP....................................................................7

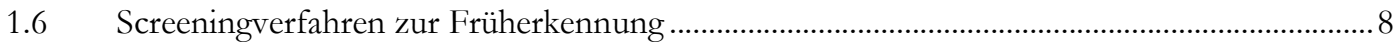

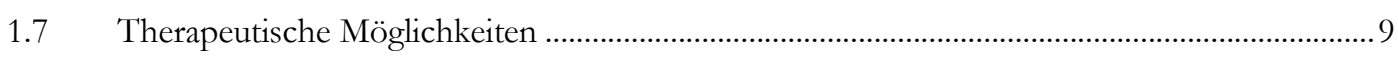

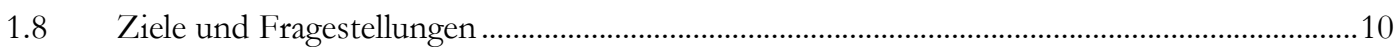

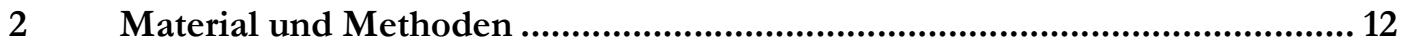

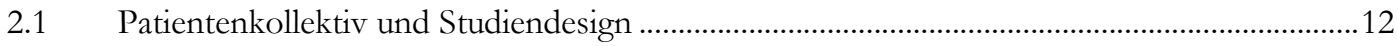

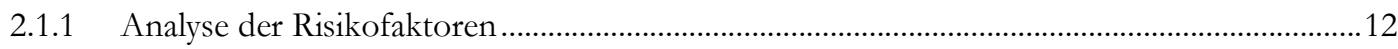

2.1.2 Analyse des Screeningverfahrens .........................................................................................

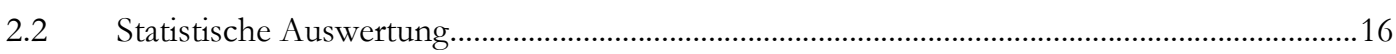

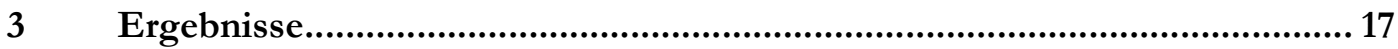

3.1 Demographische Daten des Patientenkollektivs .......................................................................17

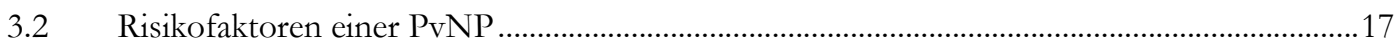

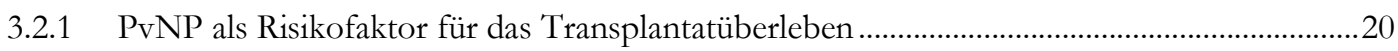

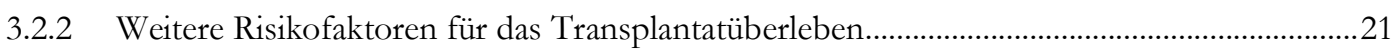

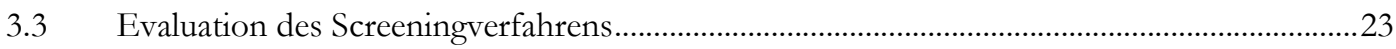

3.3.1 PvNP-Patienten vor und nach Einführung des Screeningverfahrens ......................................2

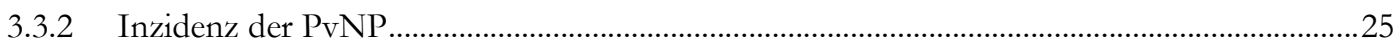

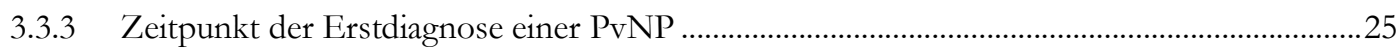

3.3.4 Outcome und Langzeitüberleben der nierentransplantierten Patienten mit PvNP................27

3.3.5 BKV-PCR bei Nierentransplantierten mit PvNP ...................................................................... 30

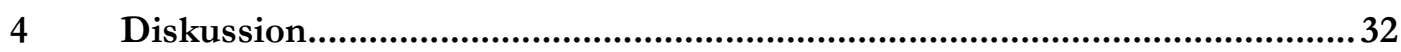

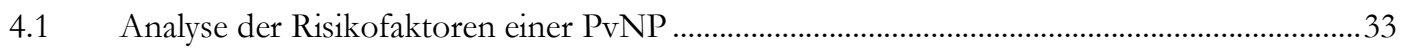

4.2 PvNP und weitere Risikofaktoren für das Transplantatüberleben............................................35

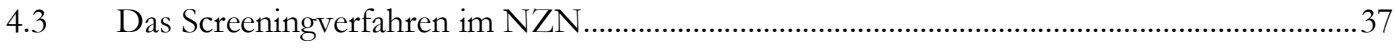

4.3.1 Evaluation des Screenings...............................................................................................

4.3.2 Empfohlener Grenzwert zur Virämiebestimmung und die PvNP............................................41 
4.4 Allgemeine Diskussion, Limitationen der Arbeit und Ausblick ..............................................4 41

$5 \quad$ Zusammenfassung............................................................................... 44

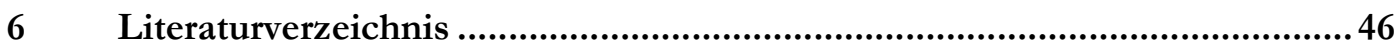




\section{Abbildungsverzeichnis}

Abbildung 1: Gruppeneinteilung der erfassten Nierentransplantierten..... 12

Abbildung 2: Darstellung des Managements der BKV-Infektion im NZN

Abbildung 3: Kaplan-Meier-Überlebenskurve: Vergleich von PvNP-Patienten und

Nierentransplantierten ohne eine PvNP (non-PvNP)

Abbildung 4: Kaplan-Meier-Überlebenskurven möglicher Risikofaktoren für das

Transplantatüberleben....

Abbildung 5: Inzidenz der PvNP in Prozent für das NZN im Beobachtungszeitraum 2003-2014 ..25

Abbildung 6: Vergleich der Zeitpunkte der Erstdiagnose in Monaten nach der Transplantation vor und nach der Einführung des Screenings.

Abbildung 7: Box-Plot der Zeitpunkte der Erstdiagnose einer PvNP mit und ohne Einsatz des

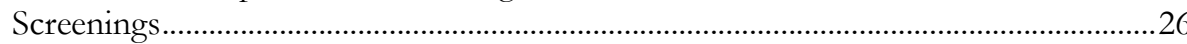

Abbildung 8: Box-Plot der Kreatininwerte in mg/dl zum Zeitpunkt der Erstdiagnose PvNP im Vergleich mit und ohne Einsatz des Screenings

Abbildung 9: Kaplan-Meier-Überlebenskurve: Vergleich der PvNP-Patienten vor und nach der Einführung des Screenings

Abbildung 10: Kaplan-Meier-Überlebenskurve: Vergleich der PvNP-Patienten vor und nach Einführung des Screenings mit Beginn des Beobachtungszeitraums ab zwei Jahren nach Transplantation.

Abbildung 11: Kaplan-Meier-Überlebenskurven: Vergleich PvNP-Patienten und Nierentransplantierte ohne eine PvNP in den Zeiträumen 2003-2010 und 20112014

Abbildung 12: Kumulierte Anzahl histologisch gesicherter PvNP-Fälle und Ergebnisse der BKVPCR bei unterschiedlichen Cut-Offs in Kopien/ml.

\section{Tabellenverzeichnis}

Tabelle 1: Beschreibung der erfassten Parameter für die Analyse möglicher Risikofaktoren einer PvNP.

Tabelle 2: Demographische Daten des gesamten Patientenkollektivs .................................................17

Tabelle 3: Analyse möglicher Risikofaktoren - Vergleich PvNP-Patienten und

Nierentransplantierte ohne PvNP.

Tabelle 4: Ergebnis der Multivariaten Modellierung aller signifikanten Risikofaktoren einer PvNP 20

Tabelle 5: Darstellung der Patientenzahlen zu verschiedenen Zeitpunkten nach der

Transplantation in Jahren

Tabelle 6: Vergleich aller PvNP-Patienten vor und nach Einführung des Screeningverfahrens........24 


\section{Abkürzungsverzeichnis}

$\begin{array}{ll}\text { ATG } & \text { Anti-Thymozyten-Globulin } \\ \text { BKV } & \text { BK-Virus, Familie der Polyomaviridae } \\ \text { CNI } & \text { Calcineurininhibitor } \\ \text { DSO } & \text { Deutsche Stiftung Organtransplantation } \\ \text { G-BA } & \text { Gemeinsamer Bundesausschuss } \\ \text { GFR } & \text { Glomeruläre Filtrationsrate } \\ \text { HLA } & \text { Humanes Leukozyten-Antigen } \\ \text { ICTV } & \text { international committee on taxonomy of viruses } \\ \text { KHM } & \text { Klinikum Hann. Münden } \\ \text { KIZ } & \text { Kalte Ischämiezeit } \\ \text { LT-Ag } & \text { Large-T-Antigen } \\ \text { MM } & \text { Mismatch } \\ \text { MMF } & \text { Mycophenolsäure } \\ \text { MNC } & \text { Medical Netcare GmbH } \\ \text { NCRR } & \text { noncoding regulatory region } \\ \text { NZN } & \text { Nephrologisches Zentrum Niedersachsen } \\ \text { PRA } & \text { panel reactive antigen } \\ \text { PvNP } & \text { Polyomavirus-Nephropathie durch das BK-Virus } \\ \text { QuaSi-Niere } & \text { Qualitätssicherung Niere } \\ \text { RF } & \text { Risikofaktor } \\ \text { st-Ag } & \text { Small-t-Antigen } \\ \text { SV40 } & \text { Simian-Virus 40 } \\ \text { Tx } & \text { Transplantation } \\ \text { WIZ } & \text { Warme Ischämiezeit }\end{array}$




\section{Einleitung}

Die Versorgung einer terminalen Niereninsuffizienz mit einer Nierenersatztherapie hat eine große gesellschaftliche Relevanz und betrifft viele Menschen in Deutschland. Zuletzt veröffentlichte Zahlen der Medical Netcare GmbH (MNC) im Auftrag des Gemeinsamen Bundesausschusses (G-BA) für das Jahr 2016 beschreiben rund 75.000 Patienten, die ambulant kontinuierlich mit einem Dialyseverfahren versorgt wurden (Potthoff et al. 2017). Diese Patienten leiden an einer Vielzahl von körperlichen und psychischen Beschwerden, wie Fatigue, Schmerzen, Schlafstörungen oder Depressivität, die die Lebensqualität insgesamt sehr stark einschränken können (Davison und Jhangri 2010). Trotz technischer Verbesserungen in den Dialyseverfahren ist die Lebenserwartung der Patienten eingeschränkt: die 5-JahresÜberlebensrate liegt bei 42,1\% (ERA-EDTA Registry 2018). Der ERA-EDTA Registry Annual Report stützt sich auf Daten vieler europäischer Staaten, jedoch beinhaltet er keine Daten aus Deutschland. Die Initiative QuaSi-Niere führte in den Jahren 1996 bis 2006 sehr ausführliche Analysen der Nierenersatztherapie in Deutschland durch und konnte in diesem Zeitraum einen jährlichen Anstieg der Prävalenz der chronischen Nierenersatztherapie von 4,4\% sowie eine Zunahme der Inzidenz von 5,1\% feststellen (Frei und Schober-Halstenberg 2008). Aktuellere Statistiken sowie Überlebensraten liegen für Deutschland nicht vor.

Die Nierentransplantation kann im Vergleich zu Dialyseverfahren sowohl die Lebensqualität (Schulz und Thaiss 2012) als auch die Lebenserwartung der Patienten mit terminaler Niereninsuffizienz steigern: Hier betragen die 5-Jahres-Überlebensraten 87,7\% bei postmortaler Spende und 94,1\% nach Lebendspende (ERA-EDTA Registry 2018). Auch diese Zahlen können nicht eins zu eins auf Deutschland übertragen werden. Der Unterschied der Überlebensraten der Nierentransplantation im Vergleich zur Dialyse muss zudem mit Vorsicht betrachtet werden. Denn um auf die Warteliste gesetzt zu werden, müssen Patienten in einem guten Allgemeinzustand sein und entsprechende Voraussetzungen erfüllen. Dadurch haben nicht transplantable Patienten bereits von ihrem Gesundheitszustand her vergleichsweise eine schlechtere Prognose. Im Jahr 2017 konnten 1.921 Patienten in Deutschland nierentransplantiert werden, 12.620 stehen auf der Warteliste (DSO 2018).

Der Erfolg der Organtransplantation in den letzten Jahrzehnten wurde zum einen durch Verbesserungen der Operationstechniken und -abläufe ermöglicht. Zum anderen spielte der Einsatz von neuen Immunsuppressiva eine große Rolle bei der Verhinderung der akuten und chronischen Abstoßungsreaktion (Hariharan et al. 2000).

Aufgrund der besseren Lebensqualität sowie auch der Lebenserwartung stellt die Nierentransplantation nach Möglichkeit die Therapie der Wahl bei terminalem Nierenversagen dar. Die nach der Transplantation notwendige immunsuppressive Therapie führt jedoch auch zu einer erhöhten Vulnerabilität gegenüber Infektionen und stellt uns dadurch vor neue Herausforderungen (Ramos et al. 2002b; Egli et al. 2007). So hat sich bei nierentransplantierten Patienten 
das BK-Virus als wichtige Infektion und Risikofaktor für das Organüberleben gezeigt (Nickeleit et al. 2000; Ramos et al. 2002a; Vasudev et al. 2005).

\subsection{Das BK-Virus: Biologie, Genetik und pathogene Mechanismen}

Das BK-Virus (BKV) gehört zur Familie der Polyomaviridae, darunter zur Spezies Human Poyomavirus 1. Neben dem BK-Virus sind 75 weitere Spezies der Polyomaviridae bekannt, die jeweils wirtsspezifisch sind. Insgesamt 13 der Spezies können den Menschen infizieren (Polyomaviridae Study Group of the ICTV et al. 2016). Ein weiteres bekanntes humanpathogenes Polyomavirus ist das JC-Virus, welches bei Immunschwäche oder Immunsuppression eine progressive multifokale Leukenzephalopathie auslösen kann (Padgett et al. 1976). Auch können verschiedene Affenarten, Fledermäuse, Nagetiere, andere Säuger, Vögel und Fische von bestimmten Polyomaviren befallen werden (Polyomaviridae Study Group of the ICTV et al. 2016).

Das Virusgenom besteht aus zirkulärer Doppelstrang-DNA und enthält eine frühe und eine späte Sequenz sowie eine noncoding regulatory region (NCRR). Die frühe Sequenz kodiert die beiden Antigene Large-T (LT-Ag) und Small-t (st-Ag), während die späte Sequenz drei virale Strukturproteine VP1, VP2 und VP3, die ein ikosaedrisches Kapsid um das Genom bilden, sowie das Agnoprotein kodiert (Seif et al. 1979). Die kodierenden Sequenzen sind genetisch stark konserviert, während die NCRR eine ausgeprägte Variabilität von 300 bis 500 Basenpaaren aufweist (Cubitt und Stoner 2006). Die frühe Sequenz wird bereits zu Beginn des Viruszyklus exprimiert. Die Transkription der späten Sequenz beginnt definitionsgemäß erst nach Beginn der viralen DNA-Replikation (Moens und Rekvig 2001).

Das LT-Ag ist ein multifunktionales Protein, welches in der viralen DNA-Replikation und Transkription eine Rolle spielt. Die verschiedenen Domänen des Proteins können darüber hinaus mit regulatorischen Proteinen der Wirtszelle interagieren und so den Zellzyklus oder die Apoptose beeinflussen. Es konnten Bindungen mit dem Rb-Protein und p53 nachgewiesen werden (Moens und Rekvig 2001).

Patienten mit einer Polyomavirus-Nephropathie (PvNP) durch das BK-Virus weisen eine durch Duplikationen, Deletionen und Mutationen veränderte NCRR im Plasma auf, während bei gesunden BKV-Trägern das Wildtyp-Fragment der NCRR nachweisbar ist (Emami et al. 2017). Das Ausmaß der Veränderung in der NCRR korreliert dabei mit der Virusaktivität und der Transkriptionsrate (Moens und Rekvig 2001).

Bei einer Infektion und Replikation des Virus können folgende zelluläre Veränderungen beobachtet werden: BK-Virione docken an die Zelloberfläche der Tubulusepithelzellen an, werden von der Zellmembran umschlossen und in Vesikeln internalisiert. Meist verbleiben einzelne Virione in eigenen Vesikeln. Sie können aber auch in komplexen membrangebundenen Aggregaten vorkommen, entweder als Tubuli mit glatten, parallelen Wänden oder gitterartig im tubuloretikulären Netz geordnet, und in der Nähe oder im Anschluss an den Golgi- 
Apparat lokalisiert sein. Dabei können die Aggregate in ihrer Größe sehr variabel sein, von wenigen Vesikeln bis zu zellkerngroßen Einschlüssen. Nicht selten sind Virione oder Virusaggregate in der Nähe des Zellkerns, in der perinukleären Zisterne oder im Zellkern selbst zu finden. Tubuläre Zellen mit einer aktiven BKV-Infektion weisen aufgrund der Entstehung neuer Viruspartikel einen vergrößerten Nukleus auf. Zellen mit großen viralen nukleären Einschlüssen lassen oftmals unterschiedliche zelluläre Schädigungsmuster erkennen: nukleäre und zytoplasmatische Schwellung, Unterbrechungen von Zellmembranen, nukleäre Einschlüsse bis hin zu Nekrosezeichen (Drachenberg et al. 2003). Da Polyomaviren nicht von einer viralen Hülle umgeben sind, ist die Freisetzung neu gebildeter Viruspartikel nur durch Lyse der Wirtszelle möglich. Daher ist die Replikation der Polyomaviren immer mit einem zytopathischen Effekt verbunden (Hirsch 2002). Durch die Lyse infizierter Zellen werden große Mengen an Virionen in den Interzellularraum oder ins Tubuluslumen freigesetzt. Der Zellzerfall führt zu einer begleitenden Entzündungsreaktion im Interstitium, an der Lymphozyten, Makrophagen und Plasmazellen beteiligt sind. Auch nicht infizierte Tubuli weisen bei Vorliegen einer PvNP in der Biopsie Schäden auf: Verlust von Zellkernpolarität, irreguläre sich überlappende Tubulusepithelien, zytoplasmatische Vakuolenbildung oder Kondensation (Drachenberg et al. 2003).

\subsection{Epidemiologie}

Der erste Nachweis des Polyomavirus gelang Gardner et al. (1971) im Urin eines Nierentransplantierten. Das neue Virus wurde nach den Initialen des Patienten B. K. benannt (Gardner et al. 1971). Eine Assoziation der Infektion mit dem BK-Virus und einer Nephropathie wurde hingegen erst einige Jahre später dokumentiert (Mackenzie et al. 1978). Durch weitere Publikationen aus verschiedenen Zentren gewann die Polyomavirus-Nephropathie vor allem in den späten 1990er Jahren an Bedeutung (Binet et al. 1999; Randhawa et al. 1999). Neben der PvNP ist das BK-Virus dafür bekannt, bei Stammzelltransplantierten eine hämorrhagische Zystitis im Verlauf auszulösen, einhergehend mit einer vermehrten Virusaktivität (Haririan und Klassen 2002). Jedoch scheint in diesem Fall die Virusreaktivierung nicht mit einer Funktionseinschränkung der Nieren assoziiert zu sein.

Eine Infektion mit dem Polyomavirus ist weit verbreitet. Die Erstinfektion findet bereits in der Kindheit statt (Gardner 1973) und wird in Verbindung mit oberen Atemwegsinfekten gebracht, die auch asymptomatisch verlaufen können (Goudsmit et al. 1982). Antikörper gegen BKV lassen sich bereits bei einjährigen Kindern nachweisen, mit zehn Jahren sind 71\% der Kinder seropositiv (Gardner 1973). Die Prävalenz steigt mit dem Alter und erreicht bis zu $75 \%$ der erwachsenen Bevölkerung weltweit. Dabei ist die Verteilung innerhalb einzelner Länder und Kontinente unterschiedlich und schwankt zwischen 46 und 94\%. Manche kleine Völ-

ker in Indien, Brasilien, Paraguay und Malaysia zeigen so gut wie gar keine Seropositivität für BKV auf (Knowles 2001). 
Das BK-Virus persistiert in den Nieren und den ableitenden Harnwegen. Ein sich schnell teilendes Gewebe, wie das Urothel, im Zusammenhang mit schwachen immunologischen Funktionen scheinen dabei die notwendigen Voraussetzungen für eine effiziente BKV-Replikation zu bilden (Hirsch 2002).

Bei immunkompetenten Individuen kann es in 5-10\% gelegentlich zu einer Reaktivierung mit einer geringen Virurie kommen, die jedoch selbstlimitierend verläuft (Polo et al. 2004). Im Falle einer Immunsuppression hingegen - beispielsweise nach einer Nierentransplantation kann das Virus reaktivieren und seine Replikation beginnen. In der Folge kommt es zur Zelllyse der Nierentubuli und einer Virurie. Das BK-Virus vermehrt sich auch im Interstitium und kann in die peritubulären Kapillaren gelangen, was zu einer Virämie führt. Ein Befall des Transplantats geht mit verschiedenen tubulointerstitiellen Schäden einher (Sawinski und Goral 2015), die üblicherweise keine Beschwerden verursachen, aber zu einer Verschlechterung der Nierenfunktion führen können (Dall und Hariharan 2008). Das Outcome hängt dabei vom Ausmaß des direkten Schadens, der Entzündungsreaktion sowie der entstehenden Fibrose ab (Sawinski und Goral 2015).

\subsection{Polyomavirus-Nephropathie (PvNP)}

Ramos et al. (2002a) fanden an der University of Maryland heraus, dass die Inzidenz der PvNP von 1\% der Nierentransplantierten im Jahr 1997 auf 5,8\% im Jahr 2001 angestiegen war. Ein Drittel der Patienten, die 1997 die Diagnose der PvNP bekamen, erlitten im Verlauf einen Funktionsverlust des Transplantats, während ein weiteres Drittel der Patienten dauerhaft ein Serumkreatinin von über $3 \mathrm{mg} / \mathrm{dl}$ aufwies. Die histologische Diagnose wurde im Mittel 14,4 Monate nach der Transplantation gestellt. Eine weitere Beobachtung war, dass Patienten mit vermehrtem Einsatz von Immunsuppressiva häufiger eine PvNP entwickelten (Ramos et al. 2002a). Einen Anstieg der Inzidenz der PvNP stellten auch Vasudev et al. (2005) fest: in den Jahren 1996 bis 2001 betrug die Inzidenz 2,3\%, während sie in den Jahren 2001 bis 2003 auf 7,9\% anstieg (Vasudev et al. 2005). In Basel fanden Prince et al. (2009) heraus, dass der erste Nachweis einer PvNP 1997 erfolgte, ein Jahr nachdem Tacrolimus und MMF immer häufiger als Basistherapie eingesetzt worden waren. Der zeitliche Zusammenhang zwischen vermehrtem Einsatz von Immunsuppressiva und dem häufigeren Auftreten von Polyomavirus-Nephropathien lässt vermuten, dass die potenten immunsuppressiven Therapeutika nicht nur drastisch die Rate der akuten Abstoßungsreaktionen gesenkt haben, sondern auch günstigere Bedingungen für die virale Replikation geschaffen haben (Ramos et al. 2002b).

Die Inzidenz der PvNP schwankt zentrumabhängig zwischen 1 und 10\% (Hirsch et al. 2013). Auch wenn die PvNP eine seltene Diagnose ist, kann sie dennoch eine wichtige Ursache einer Dysfunktion bis hin zum Verlust des Nierentransplantats sein (Nickeleit et al. 2000). In einer Publikation betrug die 5-Jahres-Überlebensrate für das Nierentransplantat bei Patienten, die an einer PvNP erkrankt waren nur 47\%, im Vergleich zu 76\% bei nicht erkrankten Nierentransplantierten (Vasudev et al. 2005). Eine weitere retrospektive Studie untersuchte 67 Patienten 
mit einer histologisch gesicherten Polyomavirus-Nephropathie. Die Inzidenz der PvNP betrug $5,1 \%$ bezogen auf alle in dem Zeitraum nierentransplantierten Patienten. Die Diagnose wurde dabei im Mittel 12,8 $( \pm 9,9)$ Monate nach der Transplantation gestellt. Im Beobachtungszeitraum von durchschnittlich einem Jahr nach Diagnosestellung verloren 16,4\% der Patienten ihr Transplantat. Außerdem zeigten PvNP-Patienten in der Kaplan-Meier-Analyse ein geringeres Überleben als Kontrollpatienten mit eingeschränkter Transplantatfunktion, bei denen jedoch kein Nachweis einer PvNP vorlag (Ramos et al. 2002b).

In den meisten Veröffentlichungen wird die Entwicklung der BKV-Reaktivierung am häufigsten innerhalb des ersten Jahres nach der Transplantation beschrieben. Beispielsweise betrug in der Untersuchung von Vasudev et al. (2005) die mediane Zeit nach der Transplantation bis zur Diagnosestellung der PvNP 318 Tage. In einer anderen Studie wurde nach der Transplantation bis zum Nachweis von decoy cells, einer BKV-Virämie und der PvNP eine mediane Zeit von 16, 23 und 28 Wochen bestimmt (Hirsch et al. 2002). Auch bei Ramos et al. (2002b) wurde die Diagnose einer PvNP im Mittel 13 Monate nach der Transplantation gestellt. Bei Prince et al. (2009) waren es durchschnittlich 283 Tage. Damit unterscheidet sich der Zeitpunkt des Auftretens deutlich von einer akuten Abstoßungsreaktion, die meist innerhalb der ersten sechs Monate nach der Transplantation beobachtet wird (Vasudev et al. 2005).

Der Nachweis einer starken Virurie, das Auftreten sogenannter decoy cells oder eine Virämie können Hinweise für eine PvNP sein (Hirsch et al. 2002). Als decoy cells werden dabei mit dem BK-Virus infizierte Tubulusepithelzellen bezeichnet, die sich in der Urinzytologie finden lassen. Sie zeigen einen großen, basophilen Zellkern mit viralen Einschlüssen und ähneln uroepithelialen Tumorzellen (Sawinski und Goral 2015). Die definitive Diagnose erfolgt allerdings durch den Nachweis von BKV-typischen zytopathologischen Veränderungen im bioptisch gesicherten Material und wird durch Immunhistochemie oder in situ Hybridisierung gesichert (Hirsch und Randhawa 2013). Da das Genom des BK-Virus zu 70\% homolog ist mit dem JCVirus und dem SV40 - zwei weiteren Polyomaviren (Cubitt und Stoner 2006) - ist es möglich, das SV40 LT-Ag als immunhistochemischen Marker in der Diagnostik der PvNP zu nutzen (Li et al. 2002).

Bei den allermeisten Patienten mit histologisch gestellter PvNP-Diagnose lassen sich decoy cells im Urin sowie eine Virurie und eine Virämie nachweisen (Drachenberg et al. 2004a). Der Verlauf der Virämie bzw. das Vorhandensein viraler DNA im Plasma spiegeln oftmals auch den Verlauf der Erkrankung wider: positiver Nachweis von BKV-DNA nach der Transplantation, das Persistieren viraler DNA im Zusammenhang mit der Entwicklung einer PvNP sowie der Rückgang viraler DNA unter der Reduktion der immunsuppressiven Therapie (Nickeleit et al. 2000). Eine Besserung der PvNP in Follow-Up-Untersuchungen geht mit einem Rückgang der viralen zytopathologischen Veränderungen in der Biopsie und einer kaum nachweisbaren viralen Replikation in der Urinzytologie oder der Virämie einher (Drachenberg et al. 2004a).

Während früher etwa 30-60\% der Patienten mit einer PvNP im Verlauf ein Organversagen entwickelten, wurden in den letzten Jahren durch die Kombination aus Screeningverfahren zur 
Früherkennung und einer schnellen Diagnosestellung sowie dem zeitnahen Einleiten von Therapiemaßnahmen deutlich bessere Outcomes erzielt (Dall und Hariharan 2008).

\subsection{Histopathologische Befunde bei PvNP}

Die Histologie einer Polyomavirus-Nephropathie wird charakterisiert durch tubuläre Atrophie und Fibrose mit einem entzündlichen Infiltrat. Der Nachweis intranukleärer BKVEinschlusskörperchen mit der Anfärbbarkeit des LT-Ag gilt als pathognomonisch für eine PvNP. Positive Biopsieergebnisse können vor allem in frühen Stadien nur fokal auftreten, wodurch die Diagnosestellung erschwert und die Wahrscheinlichkeit eines Probenfehlers erhöht wird (Sawinski und Goral 2015). Die fokalen Veränderungen können den Kortex und das Nierenmark einzeln oder beide gleichzeitig betreffen (Drachenberg et al. 2004a). Daraus lässt sich ableiten, dass eine positive Biopsie eine sichere Diagnosestellung einer PvNP erlaubt, eine negative Biopsie jedoch aufgrund des fokalen Befalls eine Nephropathie nicht ausschlieBen kann.

Lichtmikroskopisch kann eine Polyomavirus-Nephropathie nicht sicher von einer akuten Abstoßungsreaktion unterschieden werden. Eine Endarteriitis, fibrinoide vaskuläre Nekrosen, eine Glomerulitis oder CD4-Ablagerungen entlang peritubulärer Kapillaren sprechen dabei eher für eine akute Abstoßungsreaktion (Hirsch und Randhawa 2013).

Auf dem Banffer Transplantationsmeeting 2009 wurde ein Klassifikationsschema zur Stadieneinteilung der PvNP vorgeschlagen. Dieses Schema beinhaltet drei Stadien: ein frühes (Stadium A), ein florides (Stadium B) und ein spätes, sklerosierendes (Stadium C). Im Stadium A findet die virale Replikation statt. Es sind intranukleäre Einschlusskörperchen nachweisbar. Immunhistochemisch ist das SV40-LT-Ag positiv. In diesem Stadium ist kaum eine Zelllyse oder eine Freilegung tubulärer Basalmembran darstellbar. Der Banffer Chronizitätsscore beträgt <ci3 und ct3. Das Stadium B ist gekennzeichnet durch die virale Replikation im Kortex und/oder im Nierenmark, Zelllyse des Tubulusepithels sowie einer Freilegung der tubulären Basalmembran. Der Banffer Chronizitätsscore beträgt auch hier <ci3 und ct3. Im fortgeschrittenen Stadium $\mathbf{C}$ geht die virale Replikation deutlich zurück und ist kaum mehr nachweisbar. Dafür treten chronische Schäden in den Vordergrund, der Banffer Chronizitätsscore $=$ ci3 und ct3 (Sis et al. 2010). Sar et al. (2011) haben das Bannfer Klassifikationsschema auf seine Interobserver-Reliabilität überprüft. Es wurden 24 Biopsien mit histologisch gesicherter PvNP von vier voneinander unabhängigen Nierenpathologen untersucht und eine Stadieneinteilung vorgenommen, ohne etwas über die Klinik der Patienten zu wissen. Es ergab sich dabei ein Kappa-Score von 0,47 (95\%-Konfidenzintervall, 0,35-0,60; $<<0,001$ ) (Sar et al. 2011).

Das Langzeitüberleben korreliert mit dem Stadium der Nephropathie sowie mit dem Vorhandensein chronischer Schäden (Stadium C) (Scadden et al. 2017). Fortgeschrittene tubulointerstitielle Atrophie, aktive Inflammation und höhere Kreatininspiegel gehen mit einem schlechteren Outcome und einem deutlich häufigeren Organverlust einher (Drachenberg et al. 2004a). 


\subsection{Risikofaktoren für die Entwicklung einer PvNP}

Da die PvNP vor allem bei Nierentransplantierten ein wichtiges Krankheitsbild darstellt und gleichzeitig bei anderen Organtransplantationen kaum eine Rolle spielt, scheint es naheliegend, dass es spezifische Risikofaktoren gibt, die mit der Transplantation genau dieses Organs in Verbindung stehen (Hirsch und Randhawa 2013). Auch wenn es keinen allgemeinen Konsens über genau definierte Risikofaktoren gibt (Schold et al. 2009), wird über viele Studien hinweg als wichtigster Risikofaktor für die Entstehung einer PvNP der Grad der Immunsuppression beschrieben (Wiseman 2009).

Es zeigen sich Unterschiede bezüglich der Inzidenz sowie weiterer möglicher Risikofaktoren der PvNP zwischen verschiedenen Transplantationszentren. Dies kann durch die Variabilität der immunsuppressiven Therapie und des Managements einer BKV-Infektion bedingt sein (Hirsch und Randhawa 2013). Ramos et al. (2002b) beobachteten, dass PvNP-Patienten signifikant häufiger dem männlichen Geschlecht angehören und ein höheres Alter aufweisen. Eine andere kleine prospektive Studie konnte hingegen als einzigen Risikofaktor für die Entstehung einer PvNP den Einsatz von Kortikosteroiden zur Therapie der akuten Abstoßungsreaktion zeigen (Hirsch et al. 2002).

Schold et al. (2009) veröffentlichten eine Analyse von Daten aus der nationalen Transplantationsdatenbank der USA bezüglich der Inzidenz, der Risikofaktoren für das Auftreten von BKV-Interventionen und des Outcomes von nierentransplantierten Patienten, die zwischen 2004 und 2006 eine Behandlung im Zusammenhang mit einer BKV-Infektion erhielten. Die Inzidenz der BKV-Behandlungen wuchs innerhalb des ersten Jahres von 1,6\% in den ersten sechs Monaten auf 2,6\% ein Jahr nach der Transplantation. Das 3-Jahres-Transplantatüberleben unterschied sich mit 79\% für Patienten mit einer BKV-Behandlung in den ersten 6 Monaten nach Transplantation zu 90\% für Patienten ohne eine BKV-Behandlung. Als Risikofaktoren konnten identifiziert werden: höheres Spenderalter, Patienten im Kindesalter, dunkle Hautfarbe, männliches Geschlecht, HLA-Mismatch sowie der Einsatz von Tacrolimus und eine Induktion mit Anti-Thymozyten-Globulin (ATG). Auch wurden akute Abstoßungsreaktionen im Vorfeld oder im Verlauf einer BKV-Behandlung häufiger beobachtet (Schold et al. 2009). Allerdings sollte hierbei angemerkt werden, dass bei dieser Studie eine nicht näher definierte Behandlung hinsichtlich BKV als Variable verwendet wurde, die per se keine Aussage über das Stadium der Erkrankung trifft, denn eine Behandlung könnte bereits beim Nachweis einer Virurie oder einer Virämie genauso erfolgt sein wie bei der Diagnosestellung einer PvNP.

In einer weiteren retrospektiven Studie wurden Daten von Patienten, die zwischen 1985 und 2005 in Basel eine Nierentransplantation erhielten $(n=880)$, untersucht. Auch hier wurden als wichtigste Risikofaktoren die akute Abstoßungsreaktion, der Einsatz von ATG als Induktionstherapie sowie Tacrolimus und MMF in der Erhaltungstherapie mit der Entstehung einer PvNP assoziiert (Prince et al. 2009). 
Hirsch et al. (2013) führten eine prospektive, multizentrische Studie durch, in der nierentransplantierte Patienten mit Basiliximab, MMF, Steroiden und 1:1 randomisiert mit Ciclosporin oder Tacrolimus behandelt wurden. Im Verlauf von zwölf Monaten nach der Transplantation wurde die Viruslast im Plasma bestimmt. Die höchsten Raten für Virurie und Virämie wurden sechs Monate nach der Transplantation gemessen. Die Werte sanken wieder im weiteren Verlauf. Bereits nach sechs Monaten unterschieden sich die beiden Gruppen, nach zwölf Monaten noch mehr: Patienten, die Tacrolimus als Teil ihrer immunsuppressiven Therapie bekamen, zeigten eine höhere Viruslast als Patienten mit Ciclosporin. Mit einer Virämie assoziiert waren außerdem ein höherer Steroideinsatz in den ersten drei Monaten nach der Transplantation, männliches Geschlecht und höheres Alter des Empfängers. Patienten, die eine Virämie entwickelten, hatten nach zwölf Monaten eine signifikant schlechtere Nierenfunktion als Patienten ohne Virämie (Hirsch et al. 2013).

Sawinski und Goral (2015) fassten verschiedene Risikofaktoren, die in anderen Zentren und Studien beschrieben wurden, zusammen. Dabei unterteilten sie die Faktoren in drei Gruppen: Spenderbezogene Risikofaktoren wie ein BKV-seropositiver Spender, das Ausmaß des HLA-Mismatchs sowie HLA C7 scheinen mit einem erhöhten Risiko für eine PvNP assoziiert zu sein. Zu den empfängerbezogenen Risikofaktoren zählen höheres Alter des Empfängers, männliches Geschlecht, ethnische Zugehörigkeit (weißer Hauttyp) und Diabetes. Bei den transplantationsbezogenen Risikofaktoren finden sich die akute Abstoßungsreaktion, die kalte Ischämiezeit, verzögerte Funktion des Transplantats, Einsatz von Uretherstents, Induktion mit ATG sowie die Tacrolimus- oder MMF-basierte immunsuppressive Erhaltungstherapie (Sawinski und Goral 2015).

\subsection{Screeningverfahren zur Früherkennung}

Da nach wie vor keine spezifische antivirale Therapie existiert, wird seit einigen Jahren der Einsatz von Screenings zur Früherkennung einer BKV-Replikation und die daraus folgende schrittweise Reduktion der immunsuppressiven Therapie empfohlen (Hirsch und Randhawa 2013; Sawinski und Goral 2015).

Das BK-Virus lässt sich im Urin und im Blut nachweisen, wobei sich in den allermeisten Fällen eine Virurie vor einer Virämie ausbildet. Die Viruslast kann mit Hilfe einer Real-TimePCR-Untersuchung bestimmt werden. Zwischen verschiedenen Laboren können sich Unterschiede ergeben, da es keine etablierten Standarduntersuchungsverfahren gibt (Sawinski und Goral 2015).

Hirsch und Randhawa (2013) haben eine Empfehlung bezüglich des Screenings auf BKVReplikation veröffentlicht: Es sollte mindestens alle drei Monate in den ersten zwei Jahren nach der Transplantation stattfinden, danach einmal jährlich bis zum Ende des fünften Jahres nach der Transplantation. Auf diese Weise sollen 80-90\% der Risikopatienten für eine PvNP frühzeitig identifiziert werden können, bevor eine Funktionseinschränkung des Nierentransplantats vorliegt. Als Screeningverfahren für die virale Replikation eignen sich entweder die 
Untersuchung des Urins auf BKV-Virurie und decoy cells oder die Untersuchung der BKVVirämie im Plasma. Bei anhaltender Virämie sollte eine Reduktion der Immunsuppression erwogen werden (Hirsch und Randhawa 2013). Um die Diagnose einer PvNP frühzeitig zu stellen, empfiehlt es sich, bei anhaltendem Nachweis von decoy cells oder einer Virämie eine Evaluation durch eine Nierenbiopsie vorzunehmen, unabhängig von der Nierenfunktion (Drachenberg et al. 2004b).

In vielen Zentren wird zur BKV-Detektion die Real-Time-PCR des Plasmas präferiert, da sich hierfür die besten Ergebnisse für die Sensitivität und Spezifität gezeigt haben (Sawinski und Goral 2015). Der Nachweis der BKV-DNA im Plasma scheint außerdem spezifisch für das Auftreten einer PvNP zu sein. In einer Untersuchung von Nickeleit et al. (2000) wurde nicht nur eine Korrelation zwischen der BKV-Detektion mittels Real-Time-PCR und der bioptischen Sicherung der Nephropathie gezeigt, sondern auch HIV-1-Patienten als Kontrollpatienten auf das Auftreten von BKV-DNA im Plasma untersucht. Bei keinem von ihnen konnte BKV im Plasma nachgewiesen werden. Ebenfalls konnte in dieser Studie gezeigt werden, dass die Virämie 16 bis 33 Wochen der histologischen Diagnose vorausgeht. Damit ist das Screening auf BKV-DNA im Plasma zur Identifizierung von Risikopatienten für eine PvNP geeignet (Nickeleit et al. 2000).

Nach den aktuellen Empfehlungen der Banff Working Group kann ab einem Wert von $\geq 4 * \log 10$ BKV-Kopien/ml (10.000 Kopien) die Diagnose einer vermutlichen PvNP gestellt werden, die bei entsprechender Indikation bioptisch gesichert werden sollte, und durch eine Reduktion der Immunsuppression den Progress zur PvNP verhindern könnte (Nickeleit et al. 2018). Eine andere Untersuchung zeigt jedoch, dass bei einem Cut-Off von 10.000 Kopien/ml viele Fälle einer PvNP nicht erfasst werden (in dieser Studie 35\% aller PvNP-Fälle), mit unter Umständen schweren Folgen für die Patienten (Hassan et al. 2014).

Ein neuer Ansatz befasst sich mit der Untersuchung von Urinzytologie und Urin-PCR als Früherkennung der BKV-Replikation (Gouvêa et al. 2016). Es könnte zukünftig vermehrt zum Einsatz kommen. Bisher gibt es jedoch nur sehr wenige Erkenntnisse darüber, wie gut die Urinuntersuchung mit der Entwicklung einer PvNP korreliert.

\subsection{Therapeutische Möglichkeiten}

Nach heutigem Wissensstand ist die Grundlage der Behandlung einer PolyomavirusNephropathie die Reduktion der Immunsuppression. Diese kann als diskontinuierliche Gabe der Antimetabolite erfolgen, als Dosisreduktion der Calcineurin-Inhibitoren um 25-50\% oder einen Wechsel von Tacrolimus auf Ciclosporin beinhalten (Sawinski und Goral 2015). Die Reduktion der Immunsuppression birgt jedoch zugleich die Gefahr der akuten oder chronischen Abstoßungsreaktion. Sowohl die PvNP als auch die Abstoßungsreaktion führen zu einer Funktionsverschlechterung des Transplantats mit tubulointerstitieller Nephritis und zum Fortschreiten der Fibrose (Bohl und Brennan 2007). 
Alternativ als sekundäre Therapiemöglichkeit können Leflunomid, Cidofovir, Ciprofloxacin, Rapamycin oder Immunglobuline i.v. gegeben werden. Eine spezifische antivirale Therapie existiert bisher nicht (Sawinski und Goral 2015).

\subsection{Ziele und Fragestellungen}

Wie bereits zu Beginn erwähnt, gilt die Nierentransplantation aufgrund der besseren Lebensqualität und Lebenserwartung als Therapie der Wahl bei terminaler Niereninsuffizienz. Zu Beginn der Transplantationsmedizin stellten akute Abstoßungsreaktionen ein großes Risiko für das Transplantatüberleben dar. Durch den Einsatz von Immunsuppressiva konnten präventiv und therapeutisch Verbesserungen erzielt werden. Zugleich - verbunden mit der immunsuppressiven Therapie - stellte sich eine erhöhte Infektanfälligkeit bei Nierentransplantierten in den Vordergrund, beispielsweise das BK-Virus und die Polyomavirus-Nephropathie, die in einem chronischen Transplantatversagen resultieren kann.

Das BK-Virus weist eine hohe Prävalenz in der Allgemeinbevölkerung auf. Bei Immunkompetenz ist die Seropositivität in der Regel nicht mit Auswirkungen auf die Nierenfunktion verbunden. Für das Organüberleben nach der Nierentransplantation ist es jedoch als Risikofaktor von Relevanz. Obwohl eine Infektion mit dem Virus und sich daraus ergebende Folgen seit mehr als 40 Jahren bekannt sind, gibt es zum Management der BKV-Infektion und der PvNP lediglich Empfehlungen, die aus verschiedenen Studien hervorgehen. Nach wie vor ist kein etablierter Standard bezüglich der Früherkennung und Therapie vorhanden. Daraus resultiert ein großes Spektrum unterschiedlicher Praktiken, die vor allem auf individuellen Erfahrungen der einzelnen Transplantationszentren basieren. Das stellt eine Herausforderung für die Nierentransplantation dar (Sharma et al. 2016).

Viele bisherige Studien beschäftigen sich mit einer vergleichsweise kleinen Patientenzahl mit einer entsprechend noch kleineren Fallzahl bioptisch gesicherter PvNP-Fälle. Auch gibt es kaum Untersuchungen bezüglich des Langzeitüberlebens von PvNP-Patienten, die über einen Beobachtungszeitraum von ein bis zwei Jahren hinausgehen.

Diese Problemfelder haben zur Entstehung dieser Arbeit geführt. In Zusammenarbeit mit Dr. P. Weithofer (Stabstelle Transplantation V2 / Klinikum Hann. Münden (KHM) / Nephrologisches Zentrum Niedersachsen (NZN)) erfolgte eine retrospektive monozentrische Analyse der BKV-Infektion in der Ausprägung einer PvNP nach Nierentransplantation. Dazu wurden Patientendaten aus dem Zeitraum 2003 bis 2014 erhoben. Diese umfassen 1222 Nierentransplantierte, von denen 71 eine histologisch gesicherte PvNP aufweisen. Ende 2010 wurde auBerdem im KHM/NZN das Management bezüglich einer BKV-Infektion verändert und ein Screeningverfahren eingeführt, welches eine Viruslast-Untersuchung im Plasma und eine Protokollbiopsie in festgelegten Abständen umfasste. Die Besonderheit dieser Studie liegt zum einen in der großen Menge der Patienten- und Fallzahl sowie der bioptischen Sicherung der PvNP. Zum anderen erlaubt der erfasste Zeitraum mit dem veränderten Management eine Evaluation des Screeningverfahrens, die bei der aktuellen Literaturlage einzigartig ist. 
Anhand der erhobenen Daten sollen folgende Hypothesen überprüft und bearbeitet werden:

1. Es gibt Risikofaktoren (empfänger-, spender-, transplantatspezifische), die die Entstehung einer PvNP begünstigen können.

2. Die immunsuppressive Basistherapie hat einen Einfluss auf die Entstehung einer PvNP.

3. Eine PvNP stellt eine Gefahr für das Transplantatüberleben dar.

4. Der Einsatz eines Screeningverfahrens bringt einen Nutzen für PvNP-Patienten mit sich und führt zu Veränderungen der Inzidenz der PvNP, des Zeitpunktes der Erstdiagnose, der Nierenfunktion sowie des Transplantat- und Langzeitüberlebens.

5. Der empfohlene Grenzwert von $10.000 \mathrm{Kopien} / \mathrm{ml}$ für die BKV-PCR-Untersuchung unterschätzt die Häufigkeit einer PvNP. 


\section{Material und Methoden}

\subsection{Patientenkollektiv und Studiendesign}

In Zusammenarbeit mit Dr. P. Weithofer vom Nephrologischen Zentrum Niedersachsen (NZN)/Klinikum Hann. Münden/Stabstelle Transplantation V2 wurden im NZN Patientendaten aus dem Zeitraum 2003 bis 2014 erhoben. Eingeschlossen wurden alle Patienten, die in diesem Zeitraum im NZN eine Nierentransplantation bekamen. Ausschlusskriterien gab es keine. Eine Zweittransplantation wurde als neuer Fall gewertet. Auf diese Weise wurden 1222 nierentransplantierte Patienten erfasst, von denen 71 im Verlauf bis Ende 2014 eine histologisch gesicherte PvNP diagnostiziert bekamen (Abbildung 1). Die histologische Befundung und Diagnosestellung erfolgten durch einen Nephro-Pathologen. Mit Beginn 2011 wurde das Management der BKV-Infektion im NZN verändert und ein Screeningverfahren eingeführt. Von den 71 PvNP-Patienten fielen 25 in den Zeitraum 2003 bis 2010 und 46 Patienten in den Zeitraum 2011 bis 2014. Anhand dieser Daten erfolgte eine retrospektive Analyse zur Polyomavirus-Nephropathie nach Nierentransplantation für das NZN. Da für die Studie personenbezogene Daten verwendet wurden, wurde ein Antrag bei der Ethikkommission eingereicht (Antragsnummer: 23/10/17). Das Votum ergab keine rechtlichen oder ethischen Bedenken gegen das Studienvorhaben. Eine Einsicht in die Patientenakten hatte nur der im NZN angestellte Arzt Dr. P. Weithofer.

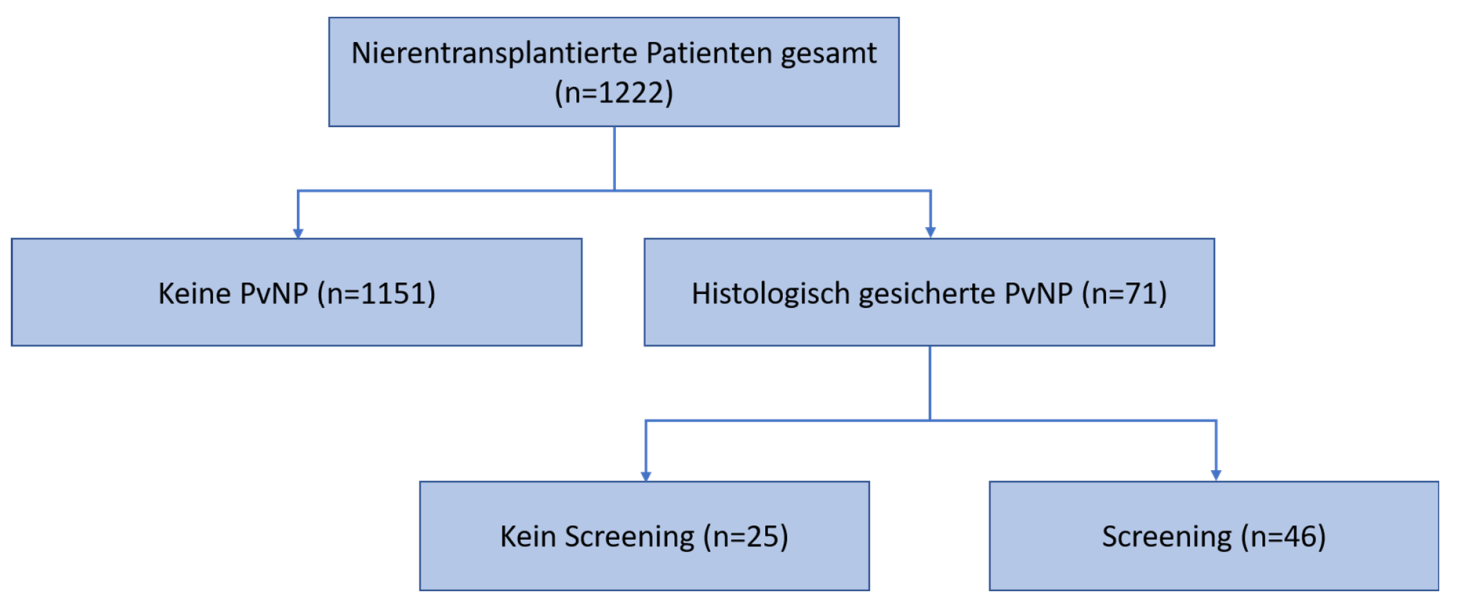

Abbildung 1: Gruppeneinteilung der erfassten Nierentransplantierten

\subsubsection{Analyse der Risikofaktoren}

Für die Untersuchung möglicher Risikofaktoren (RF), die die Entstehung einer PvNP begünstigen können, wurden Patienten mit bioptisch gesicherter PvNP ( $\mathrm{n}=71)$ und nierentransplantierte Kontrollpatienten ohne eine PvNP ( $\mathrm{n}=1151)$ miteinander verglichen. Parameter, die 
für die Analyse erfasst wurden, können in vier Gruppen eingeteilt werden: patientenspezifische, spenderspezifische, transplantatspezifische Risikofaktoren sowie die immunsuppressive Therapie. Eine genaue Beschreibung der erfassten Risikofaktoren ist in der folgenden Tabelle (Tabelle 1) dargestellt:

Tabelle 1: Beschreibung der erfassten Parameter für die Analyse möglicher Risikofaktoren einer PvNP

\begin{tabular}{|c|c|c|}
\hline & Parameter & Beschreibung \\
\hline \multirow[t]{2}{*}{ Patientensperifische RF } & Alter des Empfängers & $\begin{array}{l}\text { Alter des Empfängers zum Zeitpunkt der } \\
\text { Transplantation, als stetige Variable und } \\
\text { gruppiert nach } \geq 65 \text { Jahre vs. }<65 \text { Jahre }\end{array}$ \\
\hline & Empfängergeschlecht & $\begin{array}{l}\text { Geschlecht des Empfängers, männlich vs. } \\
\text { weiblich }\end{array}$ \\
\hline \multirow[t]{2}{*}{ Spendersperifische RF } & Alter des Spenders & $\begin{array}{l}\text { Alter des Spenders zum Zeitpunkt des } \\
\text { Todes bzw. der Transplantation, als steti- } \\
\text { ge Variable und gruppiert nach } \geq 65 \text { Jahre } \\
\text { vs. }<65 \text { Jahre }\end{array}$ \\
\hline & Spendergeschlecht & $\begin{array}{l}\text { Geschlecht des Spenders, männlich vs. } \\
\text { weiblich }\end{array}$ \\
\hline \multirow{5}{*}{$\begin{array}{l}\text { Transplantatsperifische } \\
R F\end{array}$} & Donor-Typ & postmortale Spende vs. Lebendspende \\
\hline & HLA-Merkmale & $\begin{array}{l}\text { Anzahl der HLA-Mismatchs (MM) ge- } \\
\text { samt und gruppiert nach } \geq 3 \mathrm{MM} \text { vs. }<3 \\
\mathrm{MM}\end{array}$ \\
\hline & HLA-DR & $\begin{array}{l}\text { Mismatch (ein oder zwei) vs. kein Mis- } \\
\text { match für den Locus HLA-DR }\end{array}$ \\
\hline & Kalte Ischämiezeit (KIZ) & kalte Ischämiezeit in Minuten \\
\hline & Warme Ischämiezeit (WIZ) & warme Ischämiezeit in Minuten \\
\hline \multirow[t]{3}{*}{$\begin{array}{l}\text { Immunsuppressive } \\
\text { Therapie }\end{array}$} & Induktionstherapie & $\begin{array}{l}\text { Induktion mit ATG oder Basiliximab vs. } \\
\text { keine Induktion }\end{array}$ \\
\hline & Erhaltungstherapie & $\begin{array}{l}\text { Art der Immunsuppression: Steroide/ } \\
\text { Tacrolimus/ Ciclosporin/ MMF/ Azathi- } \\
\text { oprin/ mTOR }\end{array}$ \\
\hline & Plasmapherese & Anwendung einer Plasmapherese \\
\hline
\end{tabular}


Im Anschluss wurden beide Gruppen hinsichtlich des Transplantatüberlebens untersucht, um die Hypothese zu prüfen, dass eine PvNP ein Risiko für das Transplantat darstellt. Auch wurde der Einfluss des Empfänger- und Spenderalters sowie des HLA-Mismatchs auf das Langzeitüberleben analysiert.

\subsubsection{Analyse des Screeningverfahrens}

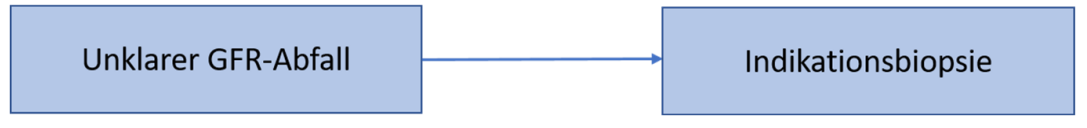

B.

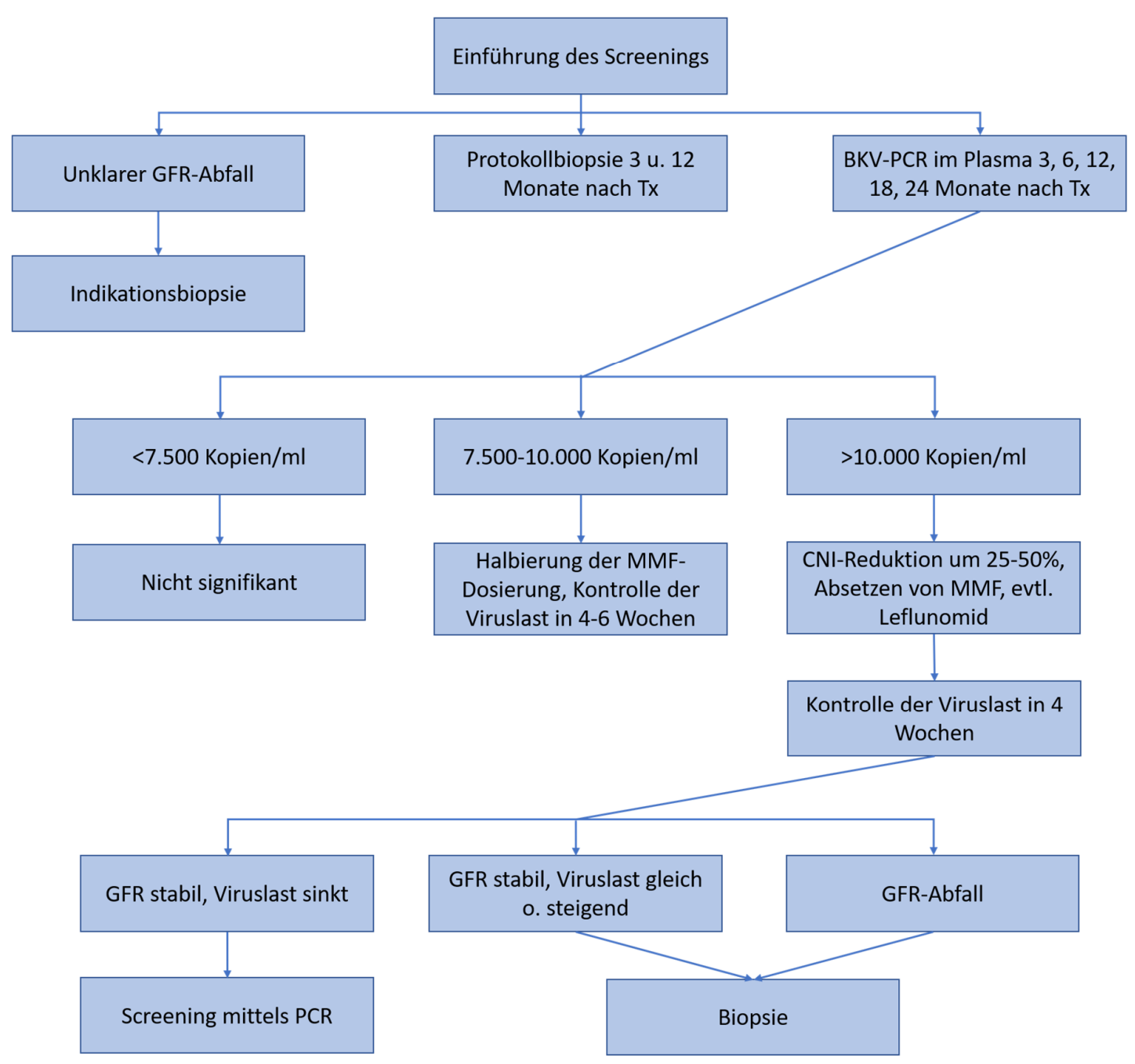

Abbildung 2: Darstellung des Managements der BKV-Infektion im NZN; $\boldsymbol{A}$. Vor Einführung des Screenings (2003-2010). B. Nach Einführung des Screenings (2011-2014). Abk: Tx - Transplantation, MMF - Mycophenolsäure, CNI - Calcineurininbibitor 
Mit Beginn 2011 wurde im NZN ein Screeningverfahren zur Früherkennung einer PvNP eingeführt. Alle Patienten, die seit Beginn 2011 transplantiert wurden, sowie Patienten, die seit 2011 eine PvNP diagnostiziert bekamen, durchliefen das Screening. Dieses beinhaltete zusätzlich zur Indikations-Biopsie bei unklarem Abfall der glomerulären Filtrationsrate (GFR) auch eine systematische Protokoll-Biopsie drei und zwölf Monate nach der Transplantation. Desweiteren wurde das EDTA-Plasma mittels PCR-Analyse auf BKV-DNA in den Zeitabständen drei, sechs, zwölf, 18 und 24 Monate nach der Transplantation untersucht. Die Analyse erfolgte im Keeser/Arndt-Labor in Hamburg. Hierbei handelte es sich um eine quantitative RealTime-PCR-Methode mit Taqman-Sonden (Kit der Firma TIB-Molbiol). Dieses Verfahren lief auf dem LightCycler 2.0 der Firma Roche. Die diagnostische Sensitivität lag dabei bei 100,0\% für Blutproben. Je nach Höhe der Viruslast wurde entsprechend weiterverfahren. Weniger als 7.500 Kopien/ml wurden als nicht signifikant gewertet. Bei 7.500-10.000 Kopien/ml wurde als Reduktion der Immunsuppression die MMF-Dosierung halbiert. Bei stabiler GFR wurde keine Biopsie durchgeführt und die Viruslast nach 4-6 Wochen kontrolliert. Wurden mehr als 10.000 Kopien/ml gemessen, so wurde die Dosis der Calcineurininhibitoren um 25-50\% reduziert, MMF abgesetzt und ein Therapieversuch mit Leflunomid gestartet. Die Viruslast wurde nach 4 Wochen erneut kontrolliert. Bei stabiler GFR und fallender Viruslast wurde weiterhin mittels PCR gescreent. Bei stabiler GFR und konstanter oder steigender Viruslast sowie bei sinkender GFR wurde eine Biopsie durchgeführt.

Im Vergleich dazu gab es im NZN in den Jahren 2003 bis 2010 kein einheitlich standardisiertes Management einer BKV-Infektion. Eine Biopsie erfolgte nur als Indikationsbiopsie beispielsweise bei unklarem Abfall der Nierenfunktion. Die jeweilige Verfahrensweise ist in $A b$ bildung 2 zusammengefasst.

Für die Untersuchung der Fragestellung, wie sich seit der Einführung des Screeningverfahrens die Inzidenz, der Zeitpunkt der Erstdiagnose, die Nierenfunktion und das Langzeitüberleben der Patienten verändert haben, wurden alle in der Studie erfassten PvNP-Patienten entsprechend dem Zeitpunkt der Transplantation bzw. der Erstdiagnose PvNP in zwei Gruppen eingeteilt (Abbildung 1). Dabei fielen 25 Patienten in den Zeitraum 2003 bis 2010 und 46 Patienten in den Zeitraum 2011 bis 2014. Um beide Gruppen miteinander vergleichen zu können, wurden diese Patienten zunächst auf Veränderungen des Kollektivs im zeitlichen Zusammenhang hinsichtlich folgender Parameter geprüft: Alter und Geschlecht des Empfängers, Alter und Geschlecht des Spenders, kalte und warme Ischämiezeit, Mismatch der HLA-Merkmale, PRA, Induktion mit ATG/Basiliximab, Art der Immunsuppression (Steroide, Tacrolimus, Ciclosporin, MMF, mTOR, Azathioprin) und stattgefundene Abstoßungsreaktion vor der Diagnose der PvNP. Danach wurde das Screeningverfahren in Bezug auf die Inzidenz, den Zeitpunkt der Erstdiagnose, die Nierenfunktion und das Transplantatüberleben evaluiert. Auch wurden Nierentransplantierte mit und ohne nachgewiesene PvNP hinsichtlich des Langzeitüberlebens einander gegenübergestellt, sowohl für den Zeitraum 2003 bis 2010 als auch für die Jahre 2011 bis 2014. Eine Follow-Up-Untersuchung wurde dafür bis August 2018 durchgeführt und beinhaltete damit mindestens einen Zeitraum von dreieinhalb Jahren. 
Patienten, die aufgrund einer anderen Ursache in dem Beobachtungszeitraum verstarben (death with graft function), wurden dennoch in die Analyse aufgenommen. Im Anschluss wurde der empfohlene Cut-Off-Wert für die BKV-PCR im Plasma von $10.000 \mathrm{Kopien/ml} \mathrm{im} \mathrm{Zusam-}$ menhang mit dem Auftreten einer PvNP auf das Patientenkollektiv im NZN angewandt.

\subsection{Statistische Auswertung}

Die Datenerhebung und -aufbereitung erfolgte mit Hilfe von Excel, für die statistische Auswertung wurde das Programm STATISTICA der Firma StatSoft in der Version 13.1 verwendet.

Für die Analyse möglicher Risikofaktoren, die die Entstehung einer PvNP fördern können, wurden PvNP-Patienten mit Nierentransplantierten ohne eine PvNP verglichen. Bei qualitativen Merkmalen, wie beispielsweise Geschlecht des Empfängers oder Donortyp, wurde mit Kreuztabellen gearbeitet. Für die Signifikanztestung wurde das Chi-Quadrat berechnet. Quantitative Merkmale, wie Alter des Empfängers oder die Ischämiezeiten, wurden bei normalverteilten Variablen mittels des t-Tests und bei nichtnormalverteilten Variablen mittels des MannWhitney-U-Tests auf Signifikanz geprüft. Zur Untersuchung der eingesetzten Immunsuppressiva als mögliche Risikofaktoren einer PvNP wurde zusätzlich eine multivariate logistische Regression mit rückwärtigem Ausschließen angewandt. Alle als signifikant getesteten Parameter wurden im Anschluss in einer weiteren multivariaten Modellierung untersucht, um gegenseitige Einflüsse zu minimieren. Ob und wie sich eine PvNP auf das Transplantatüberleben auswirkt, wurde mittels des Kaplan-Meier-Schätzers ausgewertet und mit dem Log-Rang-Test auf Signifikanz geprüft. Vergleichend wurden zusätzlich weitere Risikofaktoren für das Transplantatüberleben mit einer Kaplan-Meier-Kurve analysiert.

Zur Evaluation des Screeningverfahrens wurde zunächst ähnlich der Risikofaktoranalyse ein Vergleich der PvNP-Patienten vor und nach der Einführung des Screenings in Bezug auf zuvor genannte Parameter (s. 2.1) durchgeführt. Die Inzidenz wurde anhand der PvNP-Fälle pro Anzahl der Transplantationen für jedes Jahr berechnet und graphisch dargestellt. Zum Vergleich der Inzidenz wurde das arithmetische Mittel für die Zeiträume 2003 bis 2010 und 2011 bis 2014 gebildet. Zur Klärung der Frage, wie sich der Zeitpunkt der Erstdiagnose PvNP seit der Einführung des Screeningverfahrens verändert hat, wurden jeweils die Mittelwerte und Konfidenzintervalle in Monaten nach der Transplantation berechnet sowie ein Box-Plot zur Veranschaulichung erstellt. Der Nutzen des Screenings hinsichtlich des Langzeitüberlebens der Patienten wurde mit dem Kaplan-Meier-Schätzer analysiert. Die Signifikanztestung erfolgte mittels des Log-Rang-Tests. Zur Überprüfung des Cut-Offs der BKV-PCR wurde, soweit die entsprechenden Daten verfügbar waren, eine Graphik zu verschiedenen Grenzwerten und den dadurch erfassten PvNP-Fällen erstellt.

Für alle statistischen Tests wurden Ergebnisse mit einem p-Wert $<0,05$ als signifikant gewertet. 


\section{Ergebnisse}

\subsection{Demographische Daten des Patientenkollektivs}

Für das weitere Verständnis der nachfolgenden Ergebnisse und eine Interpretation dieser im Zusammenhang mit der Literaturlage, sind zunächst die erhobenen demographischen Daten der Nierentransplantierten dargestellt (Tabelle 2).

Tabelle 2: Demographische Daten des gesamten Patientenkollektivs; die Daten sind als Anzahl n (\%) oder als Mittelwert \pm Standardabweichung angegeben

\begin{tabular}{ll}
\hline Parameter & Anzahl n (\%) / Mittelwert \pm SD \\
\hline Gesamtzahl Nierentransplantierte & 1222 \\
PvNP & $71(5,8)$ \\
Empfängeralter (Jahre) & $53,1 \pm 12,9$ \\
Empfängergeschlecht, männlich & $770(63,0)$ \\
Spenderalter (Jahre) & $53,2 \pm 15,1$ \\
Spendergeschlecht, männlich & $643(52,6)$ \\
Donor-Typ, postmortal & $1015(83,1)$ \\
HLA-Mismatch (von 6) & $2,4 \pm 1,6$ \\
Kalte Ischämiezeit (Minuten) & $696,4 \pm 355,3$ \\
Warme Ischämiezeit (Minuten) & $38,3 \pm 11,8$ \\
Induktionstherapie (n) & \\
Antithymozytenglobulin & $203(16,6)$ \\
Basiliximab & $408(33,4)$ \\
Immunsuppressive Therapie (n) & \\
Tacrolimus & $596(48,8)$ \\
Ciclosporin & $552(45,2)$ \\
Mycophenolsäure & $1181(96,6)$ \\
Prednisolon & $1186(97,1)$ \\
mTOR & $24(2,0)$ \\
Azathioprin & $2(0,2)$ \\
OKT3 & $1(0,1)$ \\
Plasmapherese (n) & $51(4,2)$ \\
\hline
\end{tabular}

Von 1222 Patienten, die in dem Zeitraum 2003 bis 2014 eine Nierentransplantation im NZN bekamen, waren 770 (63\%) männlich und 452 (37\%) weiblich im mittleren Alter von 53,1 Jahren zum Zeitpunkt der Transplantation. Insgesamt entwickelten 71 Patienten im Verlauf bis Ende 2014 eine histologisch gesicherte PvNP. Damit betrug die Gesamtprävalenz in die- 
sem Kollektiv 5,8\%. Ein Follow-up wurde bis August 2018 durchgeführt und beinhaltete einen Beobachtungszeitraum von mindestens 3,5 Jahren nach der Transplantation.

In $83,1 \%$ der Fälle handelte es sich um eine postmortale Spende mit einem mittleren HLAMismatch von 2,4. Die kalte Ischämiezeit betrug durchschnittlich 696 Minuten, die warme 38 Minuten.

Eine Induktionstherapie wurde insgesamt bei 611 Patienten (50\%) durchgeführt; in 16,6\% der Fälle mit Antithymozytenglobulin (ATG) und in 33,4\% mit Basiliximab. Die immunsuppressive Erhaltungstherapie beinhaltete für 48,8\% der Patienten Tacrolimus und für 45,2\% Ciclosporin. Zusätzlich bekamen ca. 97\% Mycophenolsäure und Prednisolon. Immunsuppressiva wie mTOR, Azathioprin und OKT3 kamen nur in seltenen Fällen (0,1-2\%) zum Einsatz. Bei 51 der Nierentransplantierten (4,2\%), bei denen eine Immunisierung vorlag, wurde im Vorfeld sowie im Verlauf nach der Transplantation eine Plasmapherese durchgeführt.

\subsection{Risikofaktoren einer PvNP}

Da eine Infektion mit dem BK-Virus bei nierentransplantierten Patienten in einer PvNP und in einem akuten und/oder chronischen Transplantatversagen resultieren kann, stellte sich zunächst die Frage, ob sich bestimmte Faktoren identifizieren lassen, die die Entstehung einer PvNP begünstigen können.

Für die Analyse möglicher Risikofaktoren wurden deshalb verschiedene Parameter bei PvNPPatienten und in der Kontrollgruppe Nierentransplantierter ohne eine nachgewiesene PvNP untersucht. Wie in 2.2 beschrieben, erfolgte zuerst eine Einzelanalyse der Parameter. Dabei wurden qualitative Merkmale mittels des Chi-Quadrats und quantitative Merkmale mittels des t-Tests (normalverteilt) oder des Mann-Whitney-U-Tests (nichtnormalverteilt) auf Signifikanz hin überprüft.

PvNP-Patienten waren signifikant häufiger über 65 Jahre alt und gehörten vermehrt dem männlichen Geschlecht an. Transplantationsbezogen erwiesen sich die kalte und warme Ischämiezeit als signifikant niedriger bei PvNP-Patienten. Das immunologische Risiko mittels des HLA-Mismatchs oder des PRA-Wertes haben jeweils kein signifikantes Ergebnis gezeigt.

Weder eine Induktionstherapie mit Basiliximab oder ATG nach der Transplantation noch der Einsatz einer Plasmapherese waren als Risikofaktoren identifizierbar. An verwendeten Immunsuppressiva in der Erhaltungstherapie konnte für Tacrolimus und Ciclosporin eine Signifikanz festgestellt werden. Dabei wurde Tacrolimus häufiger in der PvNP-Patientengruppe eingesetzt, wohingegen Ciclosporin in der Kontrollgruppe vermehrt verwendet wurde (Tabelle $3)$. 
Tabelle 3: Analyse möglicher Risikofaktoren - Vergleich PvNP-Patienten und Nierentransplantierte obne $\mathrm{P} v \mathrm{NP}$; die Daten sind als Anzabl n (\%) oder als Mittelwert \pm Standardabweichung angegeben

\begin{tabular}{|c|c|c|c|}
\hline Parameter & $P v N P$ & Keine $P v N P$ & $p$-Wert \\
\hline Patientenzahl & 71 & 1151 & \\
\hline Empfängeralter (Jahre) & $53,1 \pm 14,5$ & $53,1 \pm 12,8$ & n.s. \\
\hline Empfängeralter, $\geq 65 \mathrm{~J}$. & $24(33,8)$ & $257(22,3)$ & 0,026 \\
\hline $\begin{array}{l}\text { Empfängergeschlecht, } \\
\text { männlich }\end{array}$ & $55(77,5)$ & $715(62,1)$ & 0,009 \\
\hline Spenderalter (Jahre) & $54,6 \pm 16,2$ & $53,1 \pm 15,1$ & n.s. \\
\hline Spenderalter, $\geq 65 \mathrm{~J}$ & $23(32,4)$ & $261(22,7)$ & n.s. \\
\hline $\begin{array}{l}\text { Spendergeschlecht, männ- } \\
\text { lich }\end{array}$ & $33(46,5)$ & $610(53,0)$ & n.s. \\
\hline Donor-Typ, postmortal & $56(78,9)$ & $959(83,3)$ & n.s. \\
\hline KIZ (Minuten) & $613,1 \pm 342,7$ & $701,6 \pm 355,6$ & 0,042 \\
\hline WIZ (Minuten) & $35,8 \pm 10,5$ & $38,5 \pm 11,8$ & 0,035 \\
\hline HLA-Mismatch (von 6) & $2,77 \pm 1,68$ & $2,37 \pm 1,63$ & n.s. \\
\hline HLA-Mismatch, $\geq 3$ MM & $39(54,9)$ & $576(50,0)$ & n.s. \\
\hline $\begin{array}{l}\text { HLA-DR, Mismatch (ein } \\
\text { oder zwei) }\end{array}$ & $43(60,6)$ & $727(63,2)$ & n.s. \\
\hline PRA & & & n.s. \\
\hline $0 \%-5 \%$ & $53(74,7)$ & $849(73,8)$ & \\
\hline $6 \%-84 \%$ & $14(19,7)$ & $226(19,6)$ & \\
\hline$\geq 85 \%$ & $4(5,6)$ & $76(6,6)$ & \\
\hline Induktionstherapie gesamt & $39(54,9)$ & $572(49,7)$ & n.s. \\
\hline mit ATG & $14(19,7)$ & $189(16,4)$ & n.s. \\
\hline mit Basiliximab & $25(35,2)$ & $383(33,3)$ & n.s. \\
\hline \multicolumn{4}{|l|}{ Immunsuppression } \\
\hline Tacrolimus & $50(70,4)$ & $546(47,4)$ & $<0,001$ \\
\hline Ciclosporin & $20(28,2)$ & $532(46,4)$ & 0,003 \\
\hline MMF & $69(97,2)$ & $1112(96,6)$ & n.s. \\
\hline Prednisolon & $71(100,0)$ & $1115(96,9)$ & n.s. \\
\hline mTOR & $2(2,8)$ & $22(1,9)$ & n.s. \\
\hline Azathioprin & $0(0,0)$ & $2(0,2)$ & n.s. \\
\hline OKT3 & $0(0,0)$ & $1(0,1)$ & n.s. \\
\hline Plasmapherese & $5(7,0)$ & $46(4,0)$ & n.s. \\
\hline
\end{tabular}

Zusätzlich wurden die Immunsuppressiva samt Basiliximab und ATG in einer multivariaten logistischen Regression mit rückwärtigem Ausschließen auf Signifikanz getestet. Hier blieb nur Tacrolimus mit einem $\mathrm{p}<0,001$ übrig. 
Alle Parameter, die in der Risikofaktoranalyse einen signifikanten Unterschied zeigten, wurden im Anschluss in einem weiteren multivariaten Modell mit rückwärtigem Ausschließen untersucht, um gegenseitige Einflüsse zu minimieren. Das Modell ergab eine Signifikanz für männliches Geschlecht des Empfängers sowie für den Einsatz von Tacrolimus in der immunsuppressiven Therapie. Alle anderen Parameter wurden in dem Modell nacheinander ausgeschlossen (Tabelle 4).

Tabelle 4: Ergebnis der Multivariaten Modellierung aller signifikanten Risikofaktoren einer PvNP

\begin{tabular}{llcc}
\hline Parameter & Odds Ratio & $95 \%-K I$ & $p$-Wert \\
\hline $\begin{array}{l}\text { Empfängergeschlecht, } \\
\text { männlich }\end{array}$ & 2,121 & $1,197-3,758$ & 0,010 \\
Tacrolimus & 2,648 & $1,568-4,472$ & $<0,001$ \\
\hline
\end{tabular}

\subsubsection{PvNP als Risikofaktor für das Transplantatüberleben}

Wie bereits in der Einleitung beschrieben, wurden in den vergangenen 20 Jahren viele Studien durchgeführt, die zeigen konnten, dass eine BKV-Infektion und eine PvNP eine Gefährdung für das Transplantat bei Nierentransplantierten darstellen. Bei Vorliegen einer PvNP kommt es häufiger und früher zu Einschränkungen der Nierenfunktion bis hin zum Organverlust.

Für das NZN wurde daher anhand der erhobenen Daten überprüft, ob sich eine PvNP auch in diesem Zentrum als Risikofaktor für das Transplantatüberleben nachweisen lässt. Mithilfe des Kaplan-Meier-Schätzers wurden PvNP-Patienten und Nierentransplantierte ohne eine PvNP miteinander verglichen (Abbildung 3). Dabei wurde nicht zwischen PvNP-Patienten vor und nach der Einführung des Screeningverfahrens unterschieden. Zensiert wurden die Patienten, bei denen bis zum Ende der Follow-Up-Untersuchung kein Funktionsverlust des Transplantats zu beobachten war. Patienten, die an einer anderen Ursache in dem Untersuchungszeitraum verstarben, wurden in die Überlebensanalyse miteingeschlossen. Es konnte kein signifikanter Unterschied zwischen den beiden Gruppen festgestellt werden. Dennoch verliefen die Kurven nicht gleich. PvNP-Patienten wiesen ab einem Zeitpunkt von drei bis zehn Jahren nach der Transplantation schlechtere Überlebensraten auf. So betrug die 5-JahresÜberlebensrate bei PvNP-Patienten 69\%, während sie in der Kontrollgruppe bei 76\% lag. Zu späteren Zeitpunkten (neun Jahre nach der Transplantation) fanden keine Ereignisse mehr in der PvNP-Gruppe statt, was nicht zuletzt durch die deutlich geringere Patientenzahl bedingt ist. In dieser Gruppe kam es vor allem in den ersten vier Jahren zum Funktionsverlust, danach nur noch in Einzelfällen. In der Vergleichsgruppe ohne eine PvNP waren die Ereignisse aufgrund einer höheren Fallzahl über den Gesamtverlauf ausgeglichener. In der tabellarischen Ergänzung sind zum Vergleich die Patientenzahlen der beiden Gruppen, die sich noch in der Untersuchung befanden, zu verschiedenen Zeitpunkten in Jahren dargestellt (Tabelle 5). 


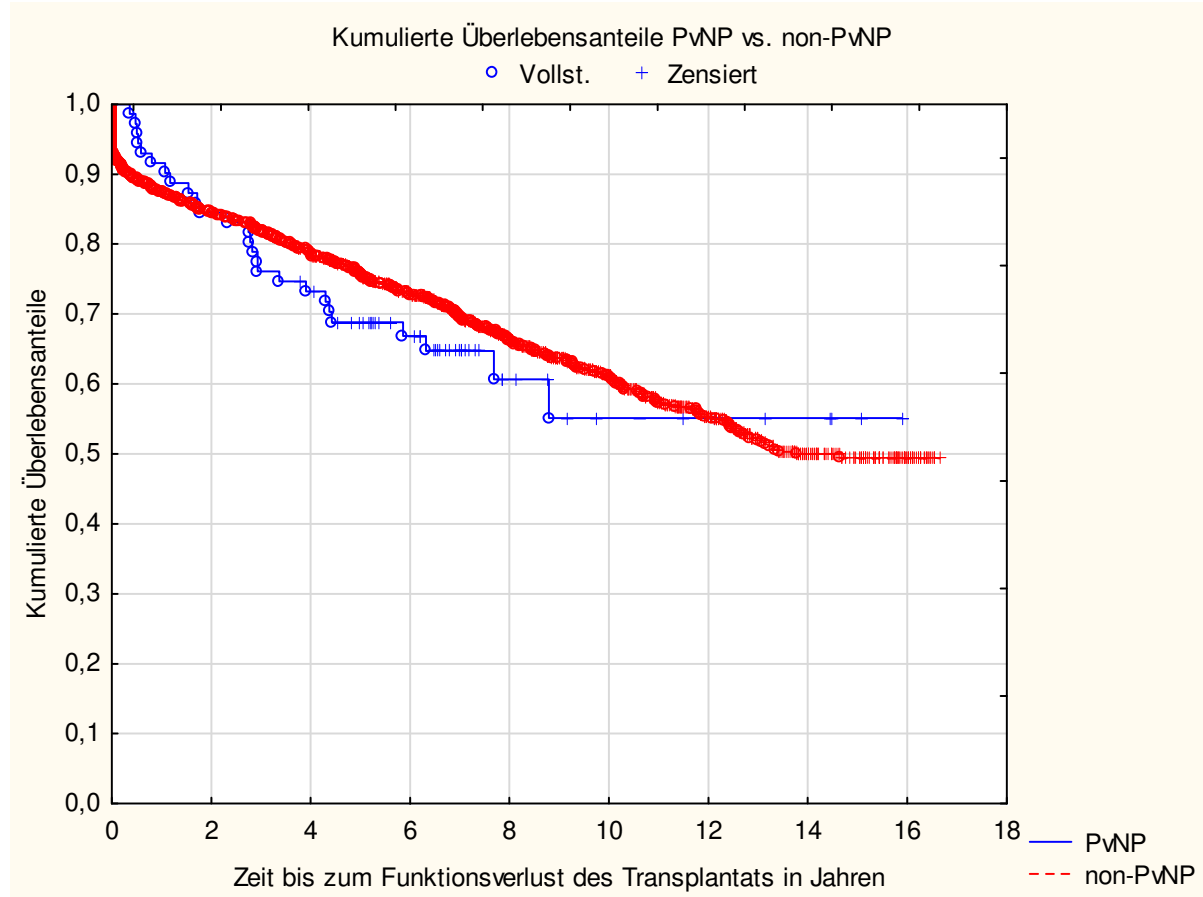

Abbildung 3: Kaplan-Meier-Überlebenskurve: Vergleich von PvNP-Patienten und Nierentransplantierten obne eine PvNP (non-PvNP); $p=0,541$ im Log-Rang-Test

Tabelle 5: Darstellung der Patientenzablen zu verschiedenen Zeitpunkten nach der Transplantation in Jabren

\begin{tabular}{lrrrrrrrr}
\hline $\begin{array}{l}\text { Zeitpunkt } \\
\text { (Jahre) }\end{array}$ & $\mathbf{0}$ & $\mathbf{2}$ & $\mathbf{4}$ & $\mathbf{6}$ & $\mathbf{8}$ & $\mathbf{1 0}$ & $\mathbf{1 2}$ & $\mathbf{1 4}$ \\
\hline PvNP & 71 & 60 & 51 & 34 & 13 & 8 & 6 & 4 \\
\hline Non-PvNP & 1151 & 973 & 895 & 734 & 523 & 368 & 228 & 109 \\
\hline
\end{tabular}

\subsubsection{Weitere Risikofaktoren für das Transplantatüberleben}

Für einen weiteren Vergleich der erfassten Kohorte mit der Literaturlage wurden ebenfalls weitere Faktoren mittels des Kaplan-Meier-Schätzers als mögliche Risikofaktoren, die das Organüberleben beeinflussen können, analysiert. Dazu zählten das Empfänger- und Spenderalter, eingeteilt in die Gruppen der $\geq 65$-Jährigen und <65-Jährigen, sowie der HLA-Mismatch, $\geq 3$ und $<3$ Mismatchs. Für alle drei Faktoren konnte ein signifikanter Einfluss beobachtet werden (Abbildung 4). Der p-Wert lag im Log-Rang-Test jeweils bei <0,001. Dabei gehen die Überlebenskurven für das Empfänger- und Spenderalter besonders stark auseinander. Die jeweiligen Gruppengrößen sind in allen drei Untersuchungen ausgewogen, sodass der zuvor beschriebene Bias an dieser Stelle entfällt. 


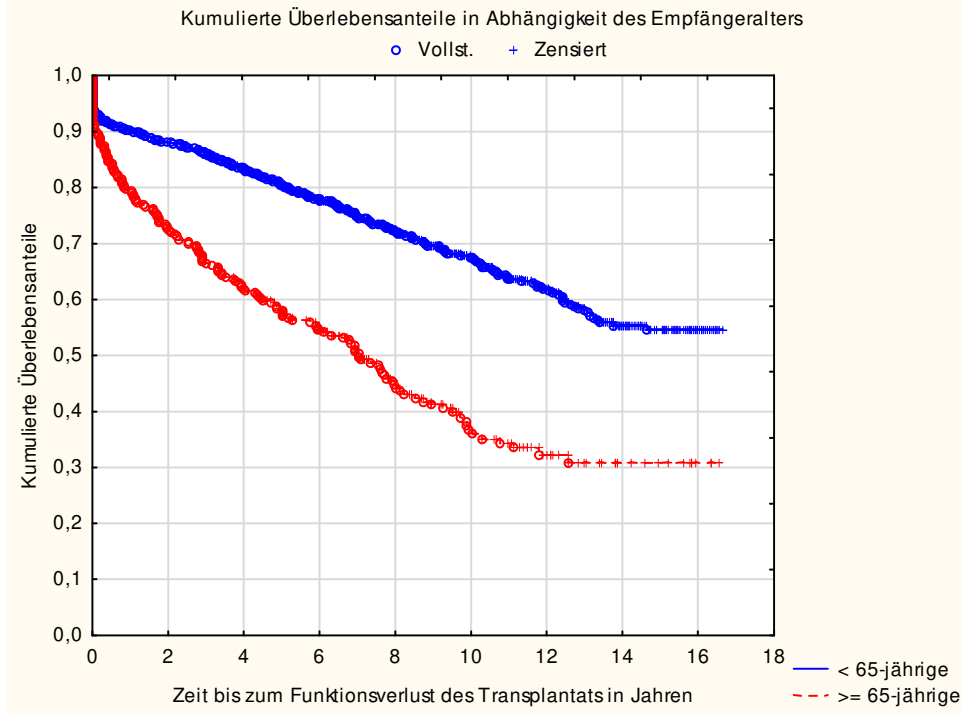

A.

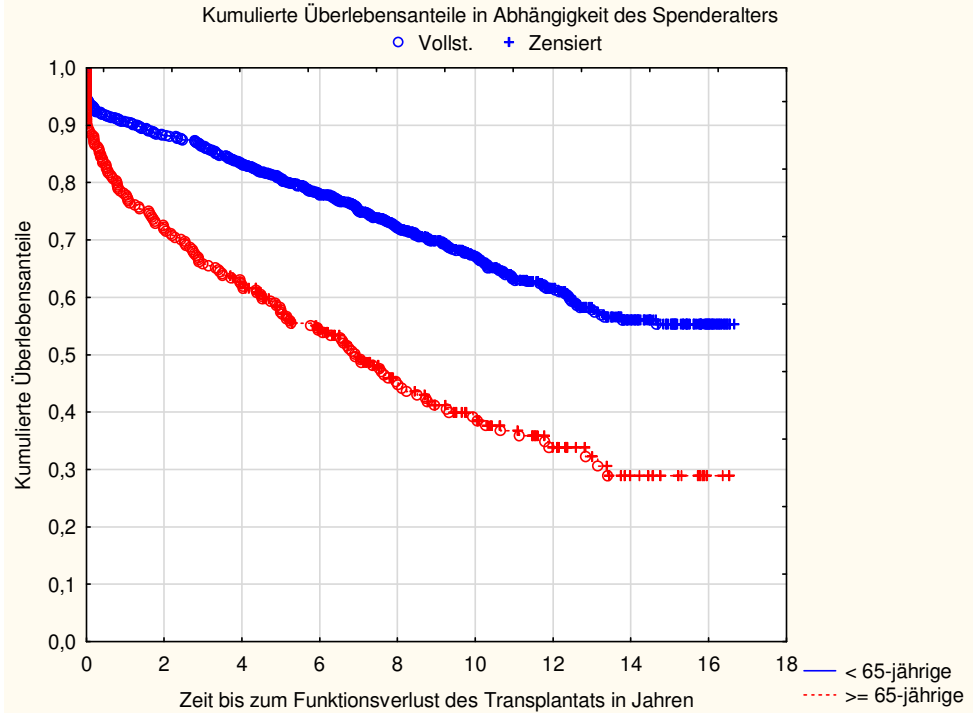

B.

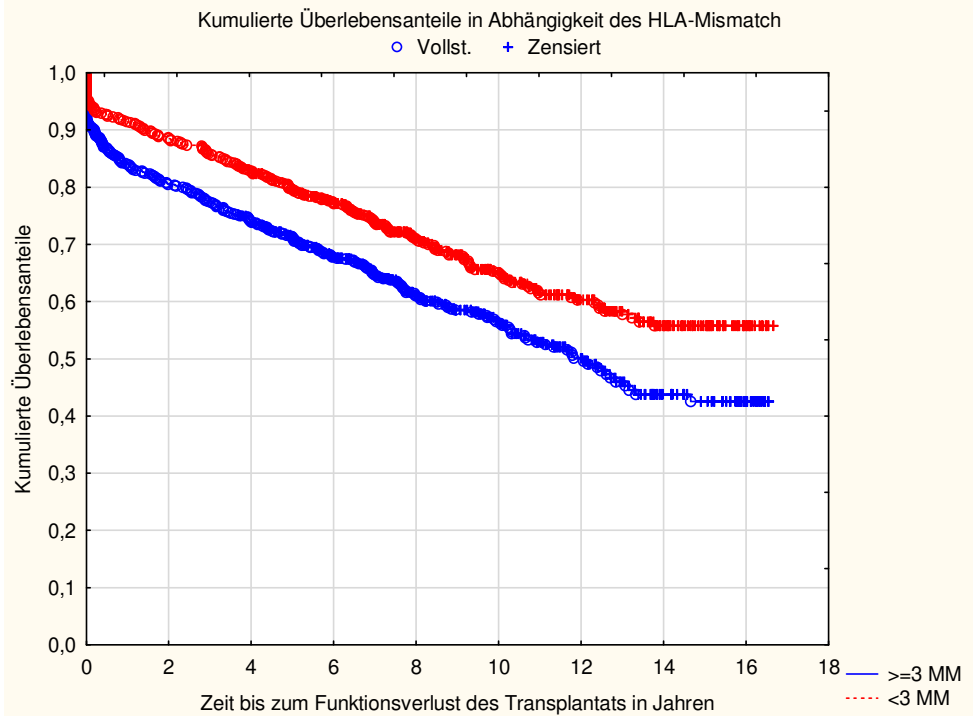

C. 
Abbildung 4: Kaplan-Meier-Überlebenskurven möglicher Risikofaktoren für das Transplantatüberleben; A: Abhängigkeit vom Empfängeralter, B: Abhängigkeit vom Spenderalter, $\boldsymbol{C}:$ Abbängigkeit von der Anzabl des HLA-Mismatchs; jeweils $p<0,001$ im Log-Rang-Test

\subsection{Evaluation des Screeningverfahrens}

Die immunsuppressive Therapie nach einer Nierentransplantation kann zur Reaktivierung einer BKV-Infektion beitragen, die in eine PvNP übergehen und dadurch in einem chronischen Transplantatversagen resultieren kann. Da keine spezifische antivirale Therapie existiert, spielt die Früherkennung einer BKV-Reaktivierung eine besondere Rolle, um Behandlungsstrategien wie die Reduktion der Immunsuppression frühzeitig zu entwickeln.

Im NZN wurde auf der Grundlage publizierter Empfehlungen im Jahr 2011 ein Screeningverfahren eingeführt. Dieses beinhaltete eine Bestimmung der Viruslast mittels einer PCRUntersuchung im Serum sowie eine zur Indikationsbiopsie zusätzliche Protokollbiopsie (Abbildung 2). Letzteres stellte eine Besonderheit dar und erlaubte eine frühzeitige histologische Diagnose einer PvNP. Genaueres zum Management der BKV-Infektion im NZN ist unter 2.1. nachzulesen.

\subsubsection{PvNP-Patienten vor und nach Einführung des Screeningverfahrens}

Um den Nutzen des Screenings evaluieren zu können, wurden zunächst alle in der Studie diagnostizierten PvNP-Fälle ( $\mathrm{n}=71$ ) in zwei Gruppen eingeteilt: PvNP-Patienten, die bis einschließlich 2010 die Diagnose gestellt bekamen $(n=25)$ - ohne ein Screening durchlaufen zu haben - und PvNP-Patienten, bei denen mit Beginn 2011 ein Screening auf BK-Viren sowie die Protokollbiopsie zum Einsatz kamen $(n=46)$. Beide Gruppen wurden auf Unterschiede hinsichtlich patienten-, spender- und transplantatspezifischer Faktoren untersucht (Tabelle ๑). Eine Signifikanzprüfung erfolgte durch einen t-Test bei quantitativen Merkmalen und durch die Bestimmung des Chi-Quadrates bei qualitativen Merkmalen.

Der Vergleich zeigte, dass sich die PvNP-Patienten nicht in allen Faktoren glichen, sondern sich im Folgenden signifikante Unterschiede ergaben: das Empfängeralter, die warme Ischämiezeit, PRA-Werte sowie der Einsatz von Tacrolimus und Ciclosporin. Zusammenfassend lässt sich beobachten, dass PvNP-Patienten seit der Einführung des Screenings signifikant älter waren, eine kürzere WIZ aufwiesen und häufiger PRA-Werte im Bereich 6-84\% hatten. Die immunsuppressive Therapie bestand seit 2011 aus deutlich vermehrtem Einsatz von Tacrolimus und weniger auf Basis von Ciclosporin. 
Tabelle 6: Vergleich aller PvNP-Patienten vor und nach Einführung des Screeningverfahrens; die Daten sind als Anzabl n (\%) oder als Mittelwert \pm Standardabweichung angegeben.

\begin{tabular}{|c|c|c|c|}
\hline Parameter & $\begin{array}{l}\text { PvNP-Gruppe obne } \\
\text { Screening bis einschl. } \\
2010\end{array}$ & $\begin{array}{l}\text { PvNP-Gruppe mit Scree- } \\
\text { ning ab } 2011\end{array}$ & $p$-Wert \\
\hline Patientenzahl & 25 & 46 & \\
\hline Empfängeralter (Jahre) & $48,1 \pm 14,7$ & $55,7 \pm 13,8$ & 0,034 \\
\hline Empfängeralter, $\geq 65 \mathrm{~J}$. & $6(24,0)$ & $18(39,1)$ & n.s. \\
\hline $\begin{array}{l}\text { Empfängergeschlecht, } \\
\text { männlich }\end{array}$ & $18(72,0)$ & $37(80,4)$ & n.s. \\
\hline Spenderalter (Jahre) & $50,7 \pm 16,8$ & $56,7 \pm 15,6$ & n.s. \\
\hline Spenderalter, $\geq 65 \mathrm{~J}$. & $6(24,0)$ & $17(37,0)$ & n.s. \\
\hline $\begin{array}{l}\text { Spendergeschlecht, } \\
\text { männlich }\end{array}$ & $13(52,0)$ & $20(43,5)$ & n.s. \\
\hline KIZ (Minuten) & $629,7 \pm 305,7$ & $604,0 \pm 362,8$ & n.s. \\
\hline WIZ (Minuten) & $42,6 \pm 12,0$ & $32,2 \pm 7,5$ & $<0,001$ \\
\hline HLA-Mismatch (von 6) & $2,64 \pm 1,63$ & $2,85 \pm 1,73$ & n.s. \\
\hline HLA-Mismatch, $\geq 3 \mathrm{MM}$ & $12(48,0)$ & $27(58,7)$ & n.s. \\
\hline $\begin{array}{l}\text { HLA-DR, Mimatch (ein } \\
\text { oder zwei) }\end{array}$ & $15(60,0)$ & $28(60,9)$ & n.s. \\
\hline PRA & & & 0,032 \\
\hline $0 \%-5 \%$ & $22(88,0)$ & $30(65,2)$ & \\
\hline $6 \%-84 \%$ & $1(4,0)$ & $14(30,4)$ & \\
\hline$\geq 85 \%$ & $2(8,0)$ & $2(4,4)$ & \\
\hline $\begin{array}{l}\text { Induktionstherapie, } \\
\text { (ATG/IL-2) }\end{array}$ & $11(44,0)$ & $28(60,9)$ & n.s. \\
\hline \multicolumn{4}{|l|}{ Immunsuppression } \\
\hline Tacrolimus & $13(52,0)$ & $37(80,4)$ & 0,012 \\
\hline Ciclosporin & $11(44,0)$ & $9(19,6)$ & 0,029 \\
\hline MMF & $23(92,0)$ & $46(100,0)$ & n.s. \\
\hline Prednisolon & $25(100,0)$ & $46(100,0)$ & n.s. \\
\hline mTOR & $2(8,0)$ & $0(0,0)$ & n.s. \\
\hline $\begin{array}{l}\text { Abstoßungsreaktion vor } \\
\text { PvNP }\end{array}$ & $11(44,0)$ & $17(37,0)$ & n.s. \\
\hline
\end{tabular}




\subsubsection{Inzidenz der PvNP}

Für den erfassten Beobachtungszeitraum 2003 bis 2014 wurde für das NZN eine jährliche Inzidenz der neu diagnostizierten PvNP-Fälle, bezogen auf die in dem jeweiligen Jahr insgesamt nierentransplantierten Patienten, berechnet. Es konnte eine stetige Zunahme der Inzidenz beobachtet werden mit einer Ausnahme im Jahr 2010 (Abbildung 5). Seit der Einführung des Screenings im Jahr 2011 verdoppelte sich der Wert im Vergleich zu den Jahren zuvor. Durchschnittlich betrug die jährliche Inzidenz 3,1\% im Zeitraum 2003 bis 2010, während sie in den Jahren 2011 bis 2014 auf 12,5\% im Mittel anstieg.

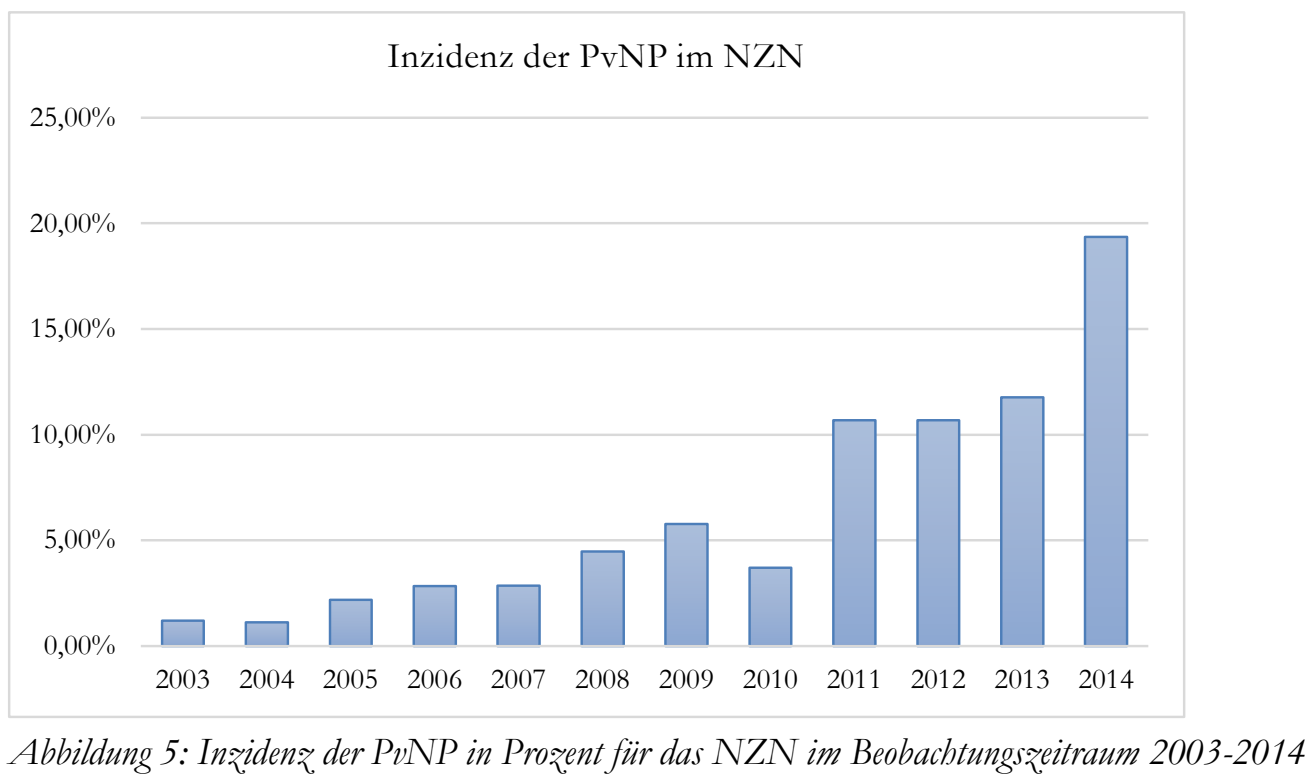

\subsubsection{Zeitpunkt der Erstdiagnose einer PvNP}

Auch der Zeitpunkt der Erstdiagnose einer histologisch gesicherten PvNP nach der Transplantation konnte durch den Einsatz des Screenings verändert werden. Vor der Einführung lag der mittlere Zeitpunkt bei 13,3 Monaten, während sich seit der Einführung der mittlere Zeitpunkt der Erstdiagnose auf 7,8 Monate verkürzte. Außerdem konnte beobachtet werden, dass der Bereich, in dem die Werte lagen - die Streuung der Werte - ebenfalls seit dem Screening geringer ausfiel: Ohne das Screening lag das 95\%-Konfidenzintervall bei 0-26,8 Monaten und mit Einsatz des Screenings bei 2-13,6 Monaten (Abbildung 6 und 7). 


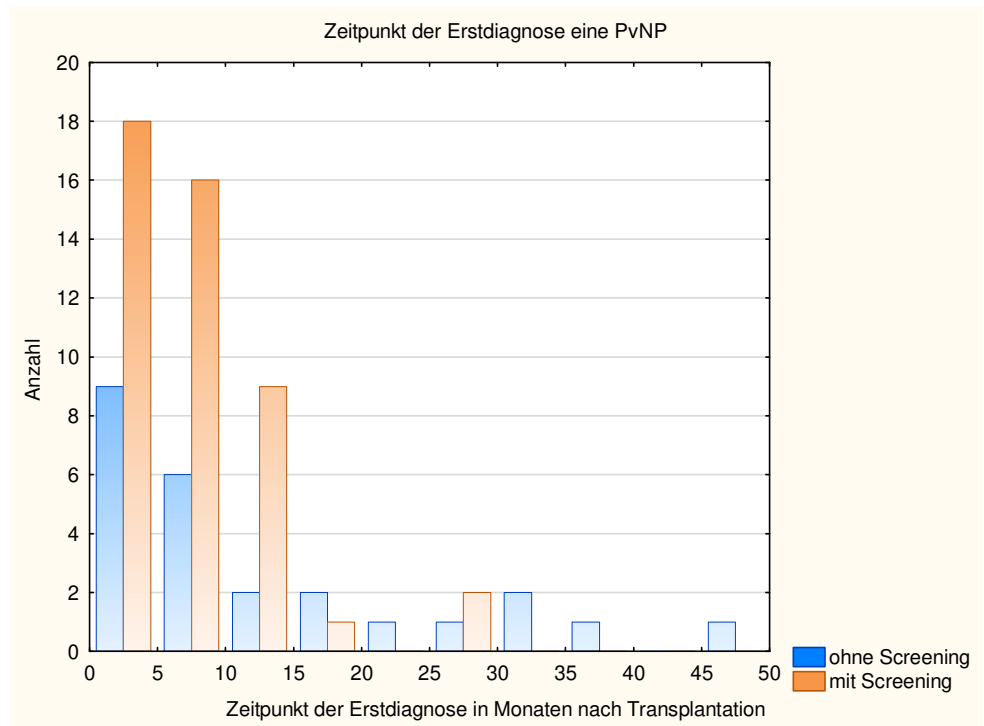

Abbildung 6: Vergleich der Zeitpunkte der Erstdiagnose in Monaten nach der Transplantation vor und nach der Einfübrung des Screenings

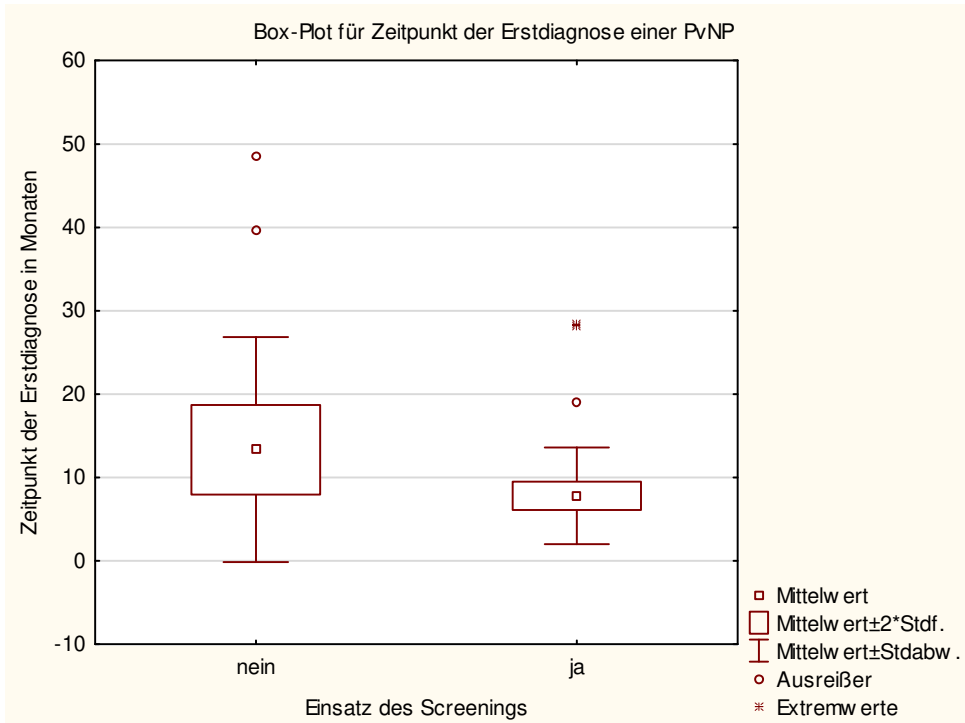

Abbildung 7: Box-Plot der Zeitpunkte der Erstdiagnose einer PvNP mit und obne Einsatz des Screenings

Desweiteren wurde die Nierenfunktion anhand der Kreatininwerte zum Zeitpunkt der Erstdiagnose PvNP erfasst. Ein Vergleich der Funktionswerte zeigte im Mittel eine geringfügige Senkung von 2,65 mg/dl vor der Einführung des Screenings auf 2,38 mg/dl seit 2011 (Abbildung 8). Im Mann-Whitney-U-Test konnte keine Signifikanz $(\mathrm{p}=0,217)$ nachgewiesen werden. 


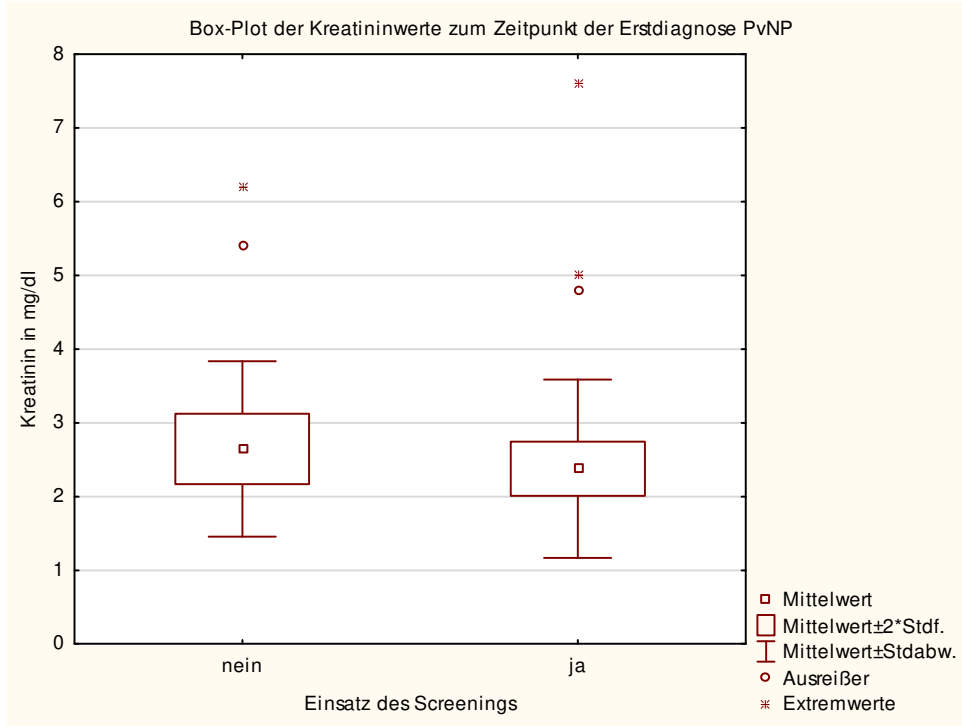

Abbildung 8: Box-Plot der Kreatininwerte in $\mathrm{mg} / \mathrm{dl}$ zum Zeitpunkt der Erstdiagnose PvNP im Vergleich mit und obne Einsatz des Screenings

\subsubsection{Outcome und Langzeitüberleben der nierentransplantierten Patienten mit PvNP}

Eine zu Beginn aufgestellte Hypothese besagt, dass ein Screeningverfahren einen Nutzen für PvNP-Patienten mit sich bringt. Entscheidend ist dabei der Einfluss auf das Langzeitüberleben der Patienten. Um sich dieser Hypothese anzunähern, wurden Kaplan-MeierKurven erstellt. Zunächst wurden PvNP-Patienten, die kein Screening durchlaufen haben ( $n=25)$, mit denen, die seit 2011 eine PvNP entwickelten ( $n=46$ ), verglichen (Abbildung 9). Als Beginn wurde der Transplantationszeitpunkt gesetzt und als Ereignis der Funktionsverlust des Transplantats gewertet. Patienten, die in dem Beobachtungszeitraum verstarben, wurden unabhängig der Todesursache in die Untersuchung aufgenommen.

In den ersten zwei bis drei Jahren nach der Transplantation verliefen beide Kurven zusammen. Im Langzeitverlauf, ab drei Jahren, zeigte sich ein Vorteil zugunsten der ScreeningGruppe (Abbildung 9). Eine Signifikanz war jedoch bisher nicht nachweisbar ( $p=0,293)$. Lässt man den Beobachtungszeitraum bei zwei Jahren nach der Transplantation beginnen, so rückt das Ergebnis $(\mathrm{p}=0,062)$ deutlich näher an die Signifikanzgrenze (Abbildung 10). Da eine PvNP vor allem eine chronische Nephropathie ist und der Schaden sich im Langzeitverlauf auf die Nierenfunktion auswirkt, erscheint diese Betrachtung durchaus sinnvoll. Dazu sollte aber auch angemerkt werden, dass die Aussagekraft der Kaplan-Meier-Überlebenskurve mit Beginn ab zwei Jahren begrenzt ist: Der Beobachtungszeitraum verkürzt sich, sodass weniger Patienten und Ereignisse für die Analyse zur Verfügung stehen. 
Kumulierte Überlebensanteile der PVNP-Patienten vor und nach Einführung des Screenings

- Vollst. + Zensiert

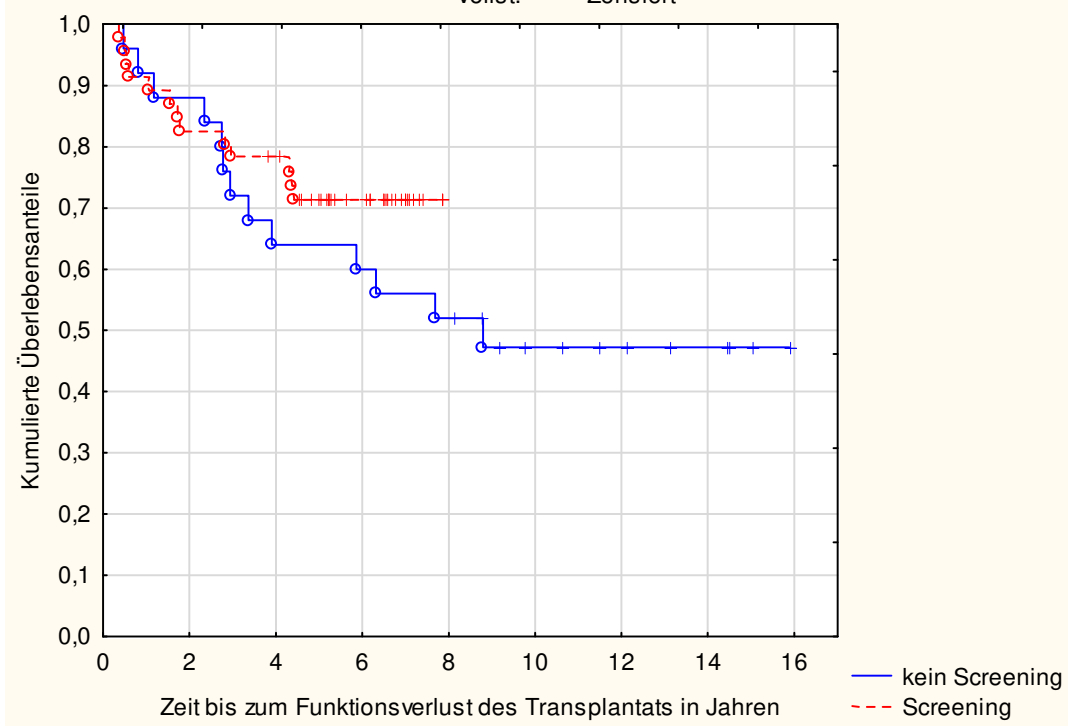

Abbildung 9: Kaplan-Meier-Überlebenskurve: Vergleich der PvNP-Patienten vor und nach der Einführung des Screenings; $p=0,293$ im Log-Rang-Test

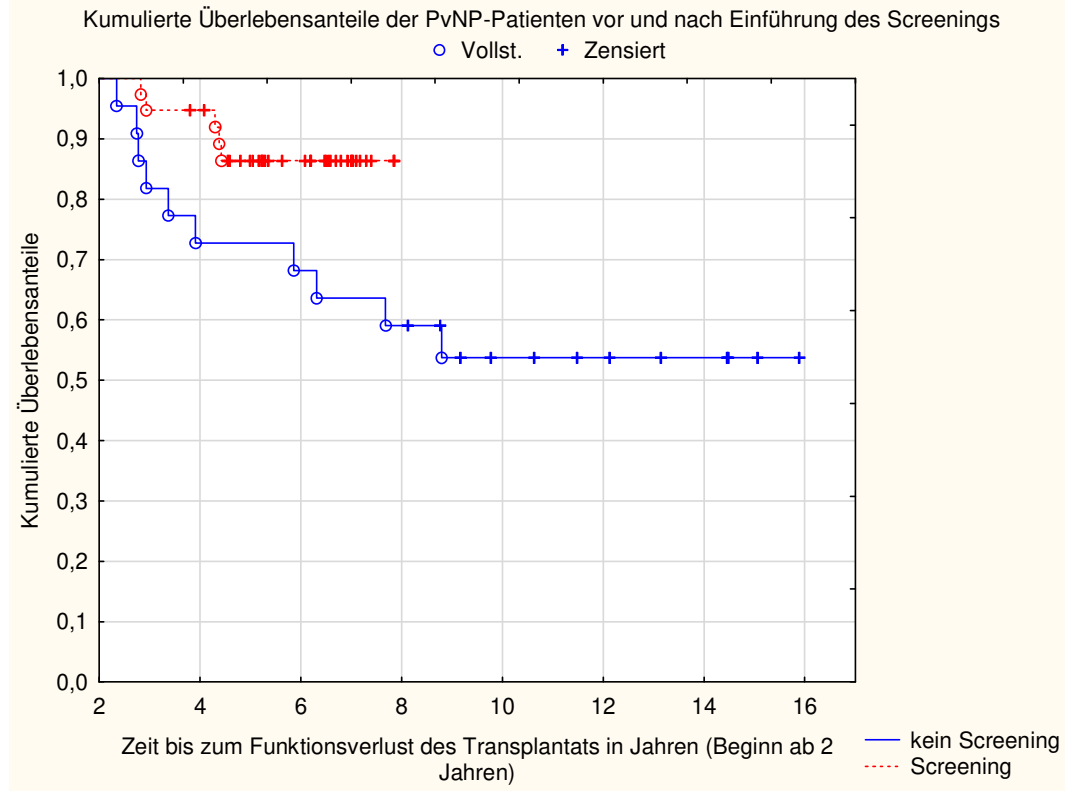

Abbildung 10: Kaplan-Meier-Überlebenskurve: Vergleich der PvNP-Patienten vor und nach Einfübrung des Screenings mit Beginn des Beobachtungszeitraums ab zwei Jahren nach Transplantation; $p=0,062$ im LogRang-Test

Eine Aussage über die mediane Überlebenszeit ist anhand der Kaplan-Meier-Kurve (Abbildung 9) nicht möglich, da nicht beide Gruppen die 50\%-Marke im Follow-Up-Zeitraum erreichen. Es können jedoch die Zeitpunkte, an denen 75\% der Patienten noch keinen Funktionsverlust des Transplantats erlitten haben, verglichen werden: Während vor der Einführung des Screenings 75\% der PvNP-Patienten bis zu 2,9 Jahren mit einem funktionierenden Trans- 
plantat lebten, verlängerte sich dieser Zeitraum auf 4,3 Jahre seit der Einführung des Screenings. Die 5-Jahres-Überlebensrate stieg von $64 \%$ auf $71 \%$.

In einer weiteren Untersuchung wurden PvNP-Patienten mit Nierentransplantierten, die keine PvNP entwickelten, bezüglich des Langzeitüberlebens verglichen, um festzustellen, ob es seit der Einführung des Screenings zu Veränderungen kam. Dabei wurden Kaplan-MeierÜberlebenskurven für die Zeiträume 2003 bis 2010 sowie für 2011 bis 2014 erstellt (Abbildung $11)$.

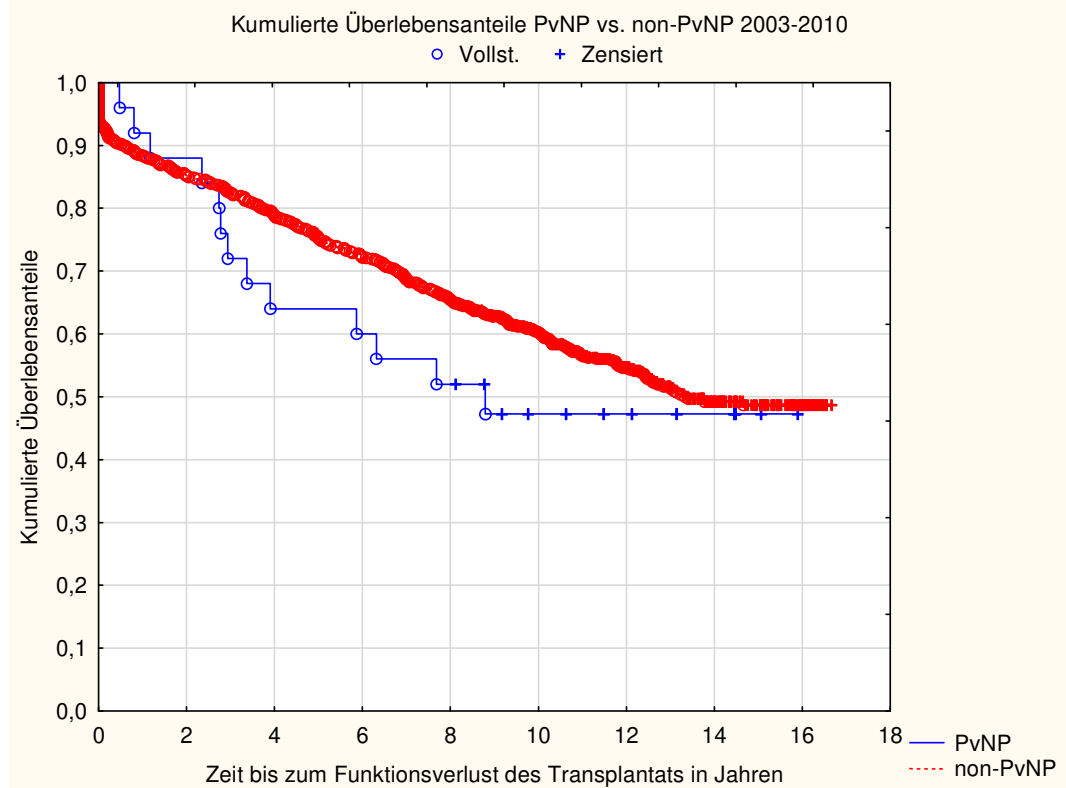

A.

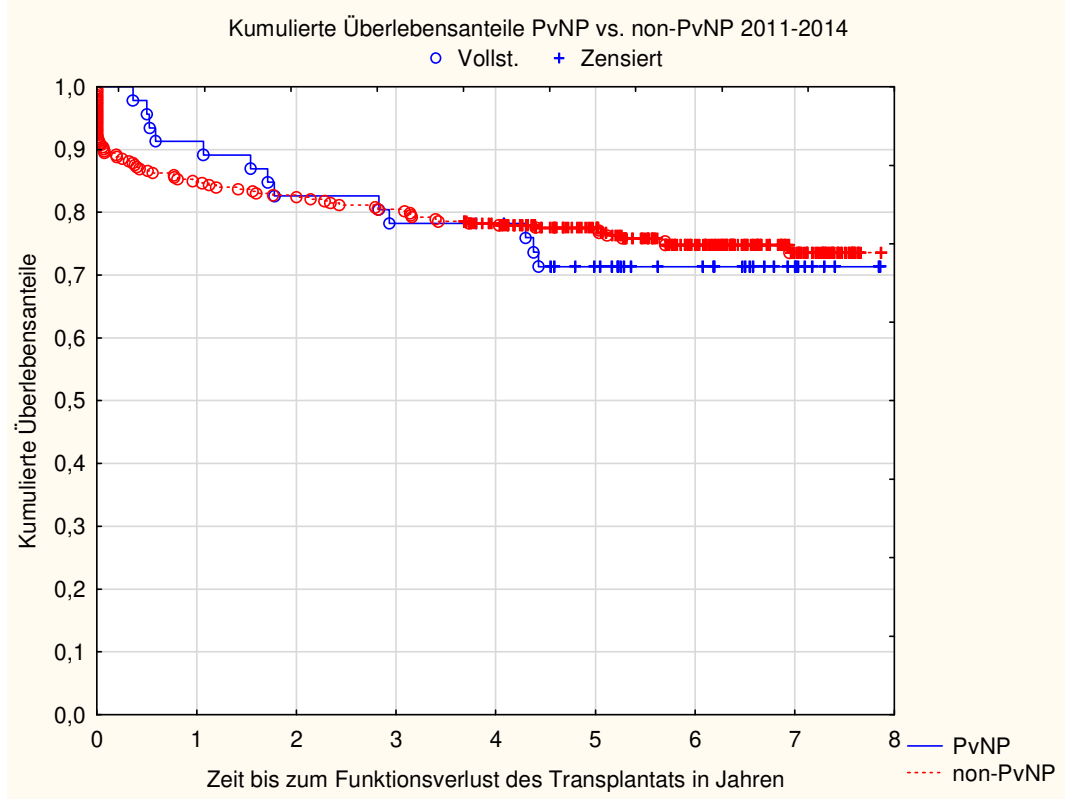

B.

Abbildung 11: Kaplan-Meier-Überlebenskurven: Vergleich PvNP-Patienten und Nierentransplantierte obne eine PvNP in den Zeiträumen A. 2003-2010 ( $p=0,389$ im Log-Rang-Test) und B. 2011-2014 ( $p=0,721$ im Log-Rang-Test) 
Das Outcome der Patienten hat sich seit dem Einsatz des Screenings durchaus verändert: seit 2011 lebten bis zum Ende der Follow-Up-Untersuchung mehr als 70\% der Patienten mit einem funktionierenden Transplantat, unabhängig davon ob sie an einer PvNP litten oder nicht. Im Vergleich dazu betrug das 70\%-Transplantatüberleben vor der Einführung des Screenings 3,4 Jahre für PvNP-Patienten und 6,7 Jahre für Nierentransplantierte ohne eine PvNP.

Obwohl der statistische Test keine Signifikanz zwischen den jeweiligen Gruppen nachweisen konnte, so zeigte sich der Verlauf des Transplantatüberlebens der PvNP-Patienten im Zeitraum 2003 bis 2010 deutlich schlechter als der für die Kontrollgruppe der Nierentransplantierten ohne eine PvNP (5-Jahres-Überlebensraten von 64\% zu 75\%). Durch die sehr ungleiche Gruppengröße sind Verzerrungen des Kurvenverlaufs nicht auszuschließen. Hier fiel auf, dass ab einem Zeitpunkt von 9 Jahren nach der Transplantation keine Ereignisse in der PvNPGruppe mehr stattfanden und sich nur noch sehr wenige Patienten in der Beobachtung befanden.

\subsubsection{BKV-PCR bei Nierentransplantierten mit PvNP}

Im Rahmen des seit 2011 angewandten Screeningverfahrens wurden PCR-Analysen auf BKVDNA in den Zeitabständen drei, sechs, zwölf, 18 und 24 Monate nach der Transplantation durchgeführt. Für 58 der 71 PvNP-Patienten konnten PCR-Daten (Kopienzahl der BKVDNA im Serum/ml) im Rahmen des Screenings zum Zeitpunkt der Erstdiagnose erhoben werden. Es wurde für diese Daten eine Unterteilung nach verschiedenen Cut-Off-Werten vorgenommen, um vergleichen zu können, wie die Ergebnisse im NZN mit den bisherigen allgemeinen Empfehlungen übereinstimmen.

Nach den Ergebnissen der Banff Working Group kann ab einem Wert von >10.000 BKVKopien/ml die Diagnose einer vermutlichen PvNP gestellt werden, die bei entsprechender Indikation bioptisch gesichert werden sollte. Die Untersuchung im NZN zeigte jedoch, dass bei einem Cut-Off von 10.000 Kopien/ml insgesamt neun PvNP-Fälle $(15,5 \%)$ mittels der PCR-Analyse nicht diagnostiziert wären (Abbildung 12). Die Diagnose konnte in diesen Fällen durch die Protokollbiopsie gestellt werden. 


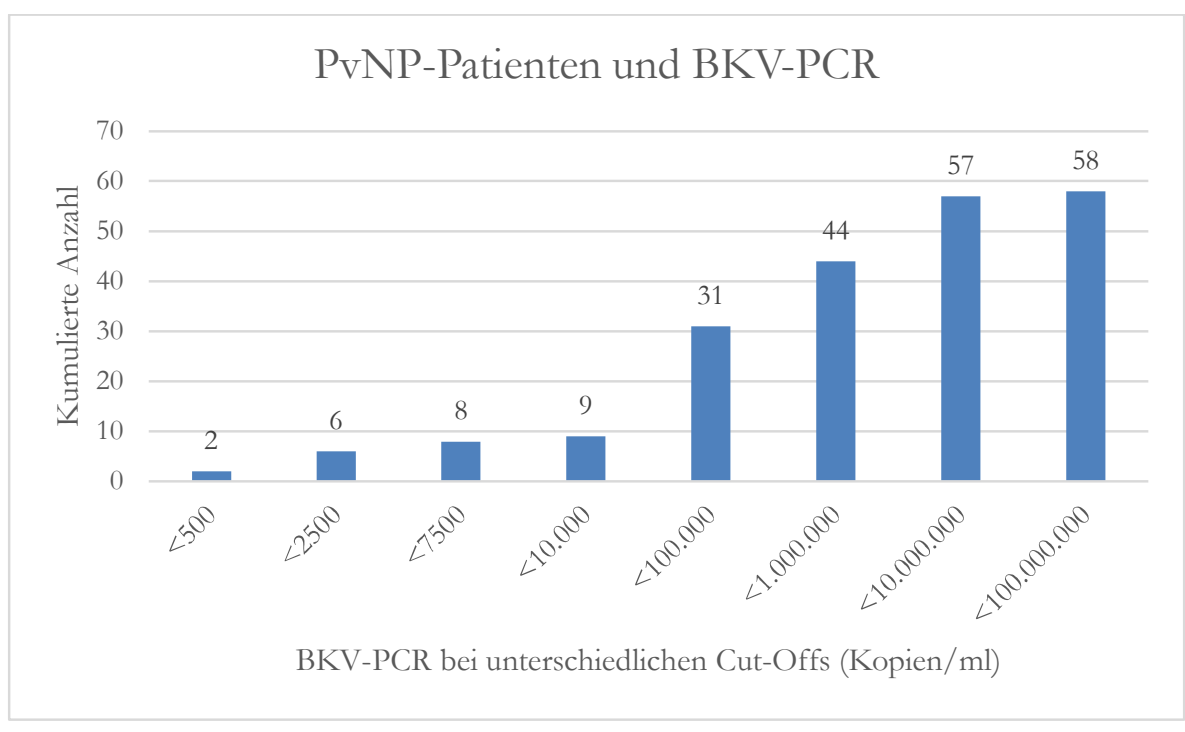

Abbildung 12: Kumulierte Anzabl histologisch gesicherter PvNP-Fälle und Ergebnisse der BKV-PCR bei unterschiedlichen Cut-Offs in Kopien / ml 


\section{Diskussion}

Das Krankheitsbild einer terminalen Niereninsuffizienz betrifft mehr als 75.000 Menschen in Deutschland (Potthoff et al. 2017), die zu einem großen Teil durch ambulante Dialyseverfahren versorgt werden und an einer Vielzahl von körperlichen und psychischen Beschwerden leiden (Davison und Jhangri 2010). Eine Nierentransplantation hingegen kann zu einer Verbesserung der Lebensqualität wie auch der Lebenserwartung dieser Patienten beitragen (Schulz und Thaiss 2012; ERA-EDTA Registry 2018) und stellt deshalb nach Möglichkeit die Therapie der Wahl bei terminalem Nierenversagen dar. Der nach einer Transplantation notwendige Einsatz an Immunsuppressiva kann das Auftreten einer akuten und chronischen Abstoßungsreaktion deutlich vermindern (Hariharan et al. 2000). Dies bringt jedoch auch eine erhöhte Vulnerabilität gegenüber Infektionen mit sich (Ramos et al. 2002b; Egli et al. 2007). Unter anderem birgt die Infektion mit dem BK-Virus in Form einer chronischen PolyomavirusNephropathie eine Gefahr für das Organüberleben (Nickeleit et al. 2000; Ramos et al. 2002a; Vasudev et al. 2005).

Das BK-Virus wurde 1971 erstmals beschrieben (Gardner et al. 1971), während das Krankheitsbild der PvNP erst Ende der 1990er Jahre an Bedeutung gewann (Binet et al. 1999; Randhawa et al. 1999). Damit stellt die PvNP ein verhältnismäßig neues Forschungsfeld dar.

Eine Infektion mit dem BK-Virus ist weit verbreitet und die Seroprävalenz schwankt je nach Region zwischen 46 und 94\% (Knowles 2001). Dennoch geht mit der Viruspersistenz für immunkompetente Individuen keine Gefahr einher (Polo et al. 2004), während bei Vorliegen einer Immunsuppression - beispielsweise nach einer Nierentransplantation - das Virus reaktivieren oder mit der Organspende übertragen werden kann. Über eine Virurie und Virämie kann sich dann eine PvNP entwickeln und zu einer Verschlechterung der Nierenfunktion beitragen (Nickeleit et al. 2000; Dall und Hariharan 2008).

Für die PvNP wird seit ihrer Entdeckung eine steigende Inzidenz beobachtet, wobei zentrumabhängig zwischen 1-10\% der Nierentransplantierten betroffen sind (Ramos et al. 2002a; Ramos et al. 2002b; Vasudev et al. 2005; Hirsch et al. 2013). Dadurch ergeben sich oftmals kleine Fallzahlen, die die Aussagekraft von Studien einschränken können. Eine weitere Schwierigkeit für die Forschung an BKV stellt die histologische Diagnosesicherung der PvNP dar, denn die Diagnose kann nur durch eine Biopsie gestellt werden, die wiederum meist nur bei einer bestehenden Indikation erfolgt. Da auf diese Weise PvNP-Patienten teilweise erst spät entdeckt oder gar übersehen werden können, wird seit einigen Jahren der Einsatz von Screeningverfahren empfohlen (Dall und Hariharan 2008). Zur Bestimmung der Viruslast kommt vor allem eine Real-Time-PCR-Untersuchung auf BKV-DNA im Serum zum Einsatz. Jedoch sind die Verfahren nicht standardisiert und es werden verschiedene PCR-Cut-Off-Werte verwendet. Eine spezifische Therapie gegen BKV gibt es nicht, stattdessen wird eine Reduktion der Immunsuppression empfohlen (Sawinski und Goral 2015). 
Das verhältnismäßig junge Forschungsfeld der PvNP mit kaum vorhandenen Untersuchungen des Langzeitüberlebens betroffener Patienten, eine hohe BKV-Seroprävalenz in der Allgemeinbevölkerung bei gleichzeitig kleinen Fallzahlen einer PvNP, die histologische Diagnosestellung sowie nach wie vor fehlende Standards bezüglich der Früherkennung und der Therapie einer PvNP stellen große Herausforderungen für die Nierentransplantation dar. Auf der Grundlage dieser Problemfelder ist die vorliegende Arbeit entstanden.

Für die retrospektive monozentrische Studie wurden im NZN/Klinikum Hann. Münden Daten aller nierentransplantierter Patienten im Zeitraum 2003 bis 2014 erhoben. Von den 1222 Nierentransplantierten haben im Verlauf 71 Patienten eine PvNP entwickelt, die histologisch gesichert werden konnte. Zunächst wurde anhand der Daten analysiert, ob bzw. welche Risikofaktoren, die eine PvNP begünstigen können, sich feststellen lassen. Auch wurde untersucht, welche Auswirkungen eine PvNP auf das Transplantatüberleben hat. Im zweiten Schritt wurde ein Screeningverfahren, welches 2011 im NZN eingeführt wurde, evaluiert. Das Screening beinhaltete eine Viruslastbestimmung mittels BKV-PCR im Serum in regelmäßigen Abständen sowie eine zusätzliche Protokollbiopsie drei und zwölf Monate nach der Transplantation. Da die Datenerhebung sowohl einen Zeitraum vor als auch nach der Einführung des Screenings erfasste, konnte ein Vergleich der Inzidenz und des Zeitpunktes der Erstdiagnose gemacht werden. Ein Follow-Up der erhobenen Daten hinsichtlich des Langzeitüberlebens wurde bis August 2018 durchgeführt und für PvNP-Patienten mit und ohne Screening analysiert. Außerdem konnten die PCR-Ergebnisse für PvNP-Patienten in Bezug auf den empfohlenen Cut-Off von 10.000 Kopien/ml, der die Diagnose einer wahrscheinlichen PvNP erlaubt, ausgewertet werden.

\subsection{Analyse der Risikofaktoren einer PvNP}

Eine Infektion mit dem BK-Virus mit der Ausprägung einer PvNP stellt ein wichtiges Krankheitsbild für nierentransplantierte Patienten dar, während sie bei anderen Organtransplantationen oder immunsupprimierten Patienten kaum eine Rolle spielt (Hirsch und Randhawa 2013). Daraus leitet sich die Hypothese ab, dass es spezifische Risikofaktoren gibt, die mit der Nierentransplantation in Verbindung stehen und die Entstehung einer PvNP begünstigen.

Die Bearbeitung dieser Hypothese ergab für das NZN in der Untersuchung einzelner Merkmale, dass PvNP-Patienten signifikant häufiger über 65 Jahre alt und männlich waren. Auch erwiesen sich die kalte und warme Ischämiezeiten bei PvNP-Patienten als signifikant niedriger im Vergleich zu Nierentransplantierten ohne eine PvNP. Die Analyse angewandter Immunsuppressiva in der Erhaltungstherapie als mögliche Risikofaktoren zeigte einen signifikant häufigeren Einsatz von Tacrolimus in der PvNP-Gruppe, wohingegen Ciclosporin vermehrt in der Kontrollgruppe verwendet wurde. Daraus lässt sich ein protektiver Effekt von Ciclosporin hinsichtlich der Entwicklung einer PvNP vermuten, während der Einsatz von Tacrolimus eher mit einer PvNP assoziiert werden kann. Untersuchungen bezüglich der Wirkung von Ciclosporin haben gezeigt, dass es auf zellulärer Ebene über eine Interaktion mit Cyclophilin A die 
Dephosphorylierung des Transkriptionsfaktors NFAT hemmt. Dadurch wird die BKVReplikation herunterreguliert (Li et al. 2012).

Zur Analyse der immunsuppressiven Therapie im NZN muss angemerkt werden, dass sich eine Aussage anhand der Daten nur bezüglich Tacrolimus und Ciclosporin treffen lässt, denn sowohl MMF als auch Prednisolon bekamen $>95 \%$ der Patienten in beiden Gruppen. Azathioprin, mTOR und OKT3 kamen nur in Einzelfällen zum Einsatz. Daher erscheint der Vergleich für diese Immunsuppressiva innerhalb der beiden Gruppen nicht als sinnvoll.

In einer anschließenden multivariaten Modellierung aller zuvor als signifikant dargestellten Faktoren konnten alle Parameter nacheinander ausgeschlossen werden, sodass sich nur eine Signifikanz für das männliche Geschlecht des Empfängers $(O R=2,121, p=0,010)$ und für den Einsatz von Tacrolimus in der immunsuppressiven Therapie $(\mathrm{OR}=2,648, \mathrm{p}<0,001)$ ergab.

$\mathrm{Da}$ es bisher keinen allgemeinen Konsens über genau definierte Risikofaktoren einer PvNP gibt, lassen sich je nach Studie und Zentrum in der Literatur unterschiedliche Ergebnisse finden (Schold et al. 2009). In vielen Studien wird jedoch der Grad der Immunsuppression und die Verwendung von Tacrolimus als möglicher Risikofaktor beschrieben (Prince et al. 2009; Schold et al. 2009; Wiseman 2009; Hirsch et al. 2013). Dies deckt sich auch mit dem Ergebnis im NZN.

Ramos et al. (2002b) beobachteten, dass PvNP-Patienten häufiger männlich waren und ein höheres Alter aufwiesen. Auch Schold et al. (2009) konnten das männliche Geschlecht neben einigen weiteren Faktoren wie höheres Spenderalter, dunkle Hautfarbe, immunologisches Risiko (HLA-Mismatch), die mit einer BKV-Behandlung in Verbindung standen, feststellen. Ethnische Unterschiede, wie das häufigere Vorkommen von BKV unter Afro-Amerikanern, stehen womöglich mit einem veränderten Stoffwechsel gegenüber dem Einsatz von Immunsuppressiva im Zusammenhang. Afro-Amerikaner weisen häufiger die Genvariante CYP3A $5 * 1$ auf und benötigen dadurch höhere Dosierungen an Tacrolimus (Maldonado et al. 2017). Eine weitere Studie zeigte, dass männliches Geschlecht und ein höheres Empfängeralter neben einem höheren Steroideinsatz nach der Transplantation mit einer höheren Viruslast assoziiert waren (Hirsch et al. 2013). Das männliche Geschlecht als möglicher Risikofaktor taucht auch bei Park et al. (2018) auf. Ein Grund für das vermehrte Auftreten von BKVInfektionen bei männlichen Nierentransplantierten könnte eine Assoziation mit einer höheren Inzidenz an obstruktiver Uropathie sein (Schold et al. 2009). Andere Studien kommen zu abweichenden Ergebnissen und beschreiben beispielsweise die akute Abstoßungsreaktion oder den Einsatz von Kortikosteroiden als mögliche Risikofaktoren einer PvNP (Hirsch et al. 2002; Prince et al. 2009). Die Variabilität an gefundenen Risikofaktoren in den einzelnen Zentren kann unter anderem durch die Unterschiede im allgemeinen und BKV-spezifischen Management bedingt sein.

Im NZN konnten vor allem das männliche Geschlecht des Empfängers sowie Tacrolimus als Immunsuppressivum als signifikante Risikofaktoren festgestellt werden. Dieses Ergebnis spiegelt sich auch in mehreren Studien wider, wenngleich es auch Untersuchungen gibt, die andere 
Beobachtungen beschreiben. Weitere Risikofaktoren, die im NZN nur in der Einzelbetrachtung als signifikant befunden wurden (Patienten über 65 Jahre, KIZ, WIZ), werden von einzelnen Zentren ebenfalls beschrieben (Sawinski und Goral 2015). Jedoch handelt es sich hierbei um Einzelerkenntnisse, die sich nicht durch viele andere Studien bestätigen lassen.

\subsection{PvNP und weitere Risikofaktoren für das Transplantatüberleben}

Eine Kaplan-Meier-Untersuchung, in der das Transplantatüberleben von PvNP-Patienten mit Nierentransplantierten ohne eine PvNP verglichen wurde, konnte im NZN keine Signifikanz dafür feststellen, dass eine PvNP ein Risiko für das Organüberleben darstellt. Die Aussagekraft dieser Untersuchung unterliegt hierbei jedoch einigen Einflüssen: Zum einen sind die Patientengruppen unterschiedlich groß. Während viele Nierentransplantierte ohne eine PvNP $(n=1151)$ erfasst wurden, hatten vergleichsweise nur 71 Patienten im Beobachtungszeitraum eine PvNP entwickelt. Dadurch fallen bereits wenige Ereignisse mehr ins Gewicht. Der Verlauf sowie die genauen Patientenzahlen zu verschiedenen Zeitpunkten zeigen, dass in der Gruppe der PvNP-Patienten es in den ersten Jahren zum Funktionsverlust kommt, während zum späteren Zeitpunkt nur noch wenige Patienten in der Untersuchung verbleiben, bei denen kein Ereignis eingetreten ist. Dies führt zu einer Verzerrung im Kurvenverlauf. Zum anderen ist die Zeitspanne der Datenerhebung relativ lang (2003 bis 2014) und umfasst zwei Zeiträume, in denen mit der PvNP unterschiedlich umgegangen wurde: Durch die Einführung eines Screeningverfahrens mit Beginn im Jahr 2011 entstand ein standardisiertes Management zur Früherkennung und Behandlung einer BKV-Infektion, wohingegen es bis Ende 2010 keine einheitliche Behandlungsstrategie gab. Jedoch wird an dieser Stelle nicht nach einem Screening unterschieden. Eine mögliche Verbesserung des Organüberlebens könnte also den Verlauf der Überlebenskurve von PvNP-Patienten beeinflussen, genauso wie allgemeine Fortschritte in der Transplantationsmedizin der letzten 15 Jahre. Hinzu kommt ein möglicher selection bias, der sogenannte immortal bias: Denn, um in die Gruppe der PvNP-Patienten zu fallen, müssen diese Patienten mindestens bis zur Diagnosestellung überlebt haben, während die Kontrollgruppe durch die Nierentransplantation direkt in die Untersuchung aufgenommen wird.

Die Studienlage ist an dieser Stelle nicht durchgehend einheitlich. Insbesondere ältere Studien berichten über verschiedene Ergebnisse, ob eine Infektion mit dem BK-Virus ein Risiko für das Transplantatüberleben darstellt. Dennoch wird überwiegend ein entsprechender Einfluss berichtet. Obwohl in vielen Fällen eine BKV-Infektion mit Uretherstenosen, vermehrtem Organverlust und einer schlechteren Nierenfunktion assoziiert wird, ist die Fallzahl in den ersten Forschungen an BKV sehr gering (zwischen 5-22 Patienten). Auch handelt es sich oftmals nur um eine Urindiagnostik und keinen histologischen Nachweis einer PvNP (Mackenzie et al. 1978; Hogan et al. 1980; Gardner et al. 1984; Binet et al. 1999; Nickeleit et al. 1999; Randhawa et al. 1999; Nickeleit et al. 2000). Eine größere, monozentrische Studie an der University of Maryland konnte über 100 PvNP-Patienten erfassen und stellte fest, dass ein Drittel 
dieser Patienten einen Transplantatverlust im Verlauf erlitt und ein weiteres Drittel Kreatininwerte über $3 \mathrm{mg} / \mathrm{dl}$ aufwies (Ramos et al. 2002a). Auch Vasudev et al. (2005) beschrieben ein deutlich schlechteres Outcome für PvNP-Patienten: während die 5-Jahres-Überlebensrate bei Nierentransplantierten ohne eine PvNP bei 76\% lag, betrug sie für PvNP-Patienten nur 47\% (Vasudev et al. 2005). Eine weitere aktuellere Studie deutet ebenfalls auf ein schlechteres Langzeitüberleben bei Vorliegen einer PvNP nach der Nierentransplantation. Allerdings sollte bei dieser Publikation die Limitation durch eine kleine Fallzahl ( $n=15)$ erwähnt werden (Park et al. 2018).

Mit Beginn des Einsatzes von Screeningverfahren und daraus ergebender Reduktion der immunsuppressiven Therapie werden bessere Überlebensraten von PvNP-Patienten beschrieben (Drachenberg et al. 2004b; Dall und Hariharan 2008; Hirsch und Randhawa 2013), was sich indirekt in dieser Analyse im NZN widerspiegelt.

Auch wenn im statistischen Test keine Signifikanz einer PvNP auf das Langzeitüberleben festgestellt werden konnte, so ist aufgrund der beschriebenen Einflüsse auf den Kurvenverlauf und der Studienlage ein Risiko für das Transplantatüberleben sehr wahrscheinlich. Die histologische Stadieneinteilung der PvNP deutet ebenfalls auf eine Nierenfunktionsverschlechterung durch chronische Veränderungen hin (Sis et al. 2010; Sar et al. 2011). Das Outcome ist dabei abhängig von dem Ausmaß des direkten Schadens, der Entzündungsreaktion sowie der entstehenden Fibrose und dem Vorhandensein chronischer Schäden (Drachenberg et al. 2004a; Bohl und Brennan 2007; Sawinski und Goral 2015; Scadden et al. 2017).

Ein weitaus größerer Einfluss $(\mathrm{p}>0,001)$ auf das Transplantatüberleben konnte im NZN für das Empfänger- und Spenderalter sowie für das immunologische Risiko (HLA-Mismatch) festgestellt werden. Zu einem ähnlichen Ergebnis kamen Trnka et al. (2018), die jedoch im Unterschied zur Studie im NZN pädiatrische Nierentransplantierte untersucht haben. Ein steigendes Alter, sowohl des Empfängers als auch des Spenders, sowie höhere HLA-MM gingen mit einem häufigeren Transplantatverlust einher (Trnka et al. 2018). Eine weitere Studie, die sich mit dem Outcome und Komplikationen bei Patienten $>60$ Jahren und $<60$ Jahren befasste, stellte ein geringeres Transplantatüberleben bei älteren Nierentransplantierten fest (Ozkul et al. 2016). Als weitere Risikofaktoren für das Langzeitüberleben werden unter anderem eine delayed graft function, das Nephron Mass Index, eine CMV-Infektion sowie akute Abstoßungsreaktionen beschrieben (Seo et al. 2015). Adipositas war ebenfalls lange Zeit mit häufigerem Organverlust, kardiovaskulären Komplikationen und einer höheren Gesamtmortalität assoziiert. Heutzutage erreichen adipöse Patienten ähnliche Überlebensraten nach einer Nierentransplantation wie nicht-adipöse Patienten (Nicoletto et al. 2014).

Dieses Ergebnis sowie die Erkenntnisse der Risikofaktorenanalyse lassen schlussfolgern, dass die durch die Datenerhebung erfasste Kohorte im NZN dem Kollektiv nierentransplantierter Patienten anderer Zentren entspricht. 


\subsection{Das Screeningverfahren im NZN}

Vor dem Hintergrund fehlender spezifischer Therapiemöglichkeiten einer BKV-Reaktivierung und PvNP wird seit einigen Jahren der Einsatz von Screeningverfahren empfohlen, um frühzeitig Behandlungsstrategien entwickeln zu können (Hirsch und Randhawa 2013; Sawinski und Goral 2015). Aufgrund dieser Empfehlungen wurden im NZN im Jahr 2011 ein Screening zur Bestimmung der BKV-Viruslast sowie eine zusätzliche Protokollbiospie drei und zwölf Monate nach der Transplantation eingeführt. Als Screeningverfahren eignen sich dabei die Untersuchung des Urins auf eine BKV-Virurie oder sogenannte decoy cells sowie die Untersuchung einer BKV-Virämie im Plasma. Letzteres wird von vielen Zentren aufgrund besserer Ergebnisse für die Sensitivität und Spezifität präferiert (Hirsch und Randhawa 2013; Sawinski und Goral 2015; Pinto et al. 2016). Auch im NZN wurde die Bestimmung der Viruslast mittels einer BKV-PCR im Plasma durchgeführt. Allgemeine Empfehlungen bezüglich einer Protokollbiopsie nach Nierentransplantation gibt es nicht. Jedoch sollte eine Indikationsbiopsie bei Verschlechterung der Nierenfunktion oder anhaltender Viruslast durchgeführt werden (Drachenberg et al. 2004b). Eine multizentrische, retrospektive Studie konnte keinen Vorteil bezüglich der Nierenfunktion und dem Vermeiden von Komplikationen durch eine Protokollbiopsie, unabhängig von einer PvNP, feststellen (Moulin et al. 2012). Eine andere Studie kam zu dem Ergebnis, dass Protokollbiopsien gerade im Zusammenhang mit der PvNP zu einer besseren Nierenfunktion und günstigeren histologischen Veränderungen im Verlauf beitragen können (Buehrig et al. 2003). Für gezielte Fragestellungen in der Forschung, insbesondere zur PvNP, die eine histologisch gestellte Diagnose ist, erscheint das Durchführen von zusätzlichen Protokollbiopsien durchaus sinnvoll. Nankivell et al. (2017) bedienten sich beispielsweise routinierten zusätzlichen Biopsien, um den Verlauf einer PvNP, die Viruslast im Gewebe sowie die Beziehung zwischen Virämie und Histopathologie zu untersuchen (Nankivell et al. 2017).

\subsubsection{Evaluation des Screenings}

Um das Screeningverfahren im NZN zu evaluieren, wurden zunächst PvNP-Patienten mit und ohne ein Durchlaufen des Screenings miteinander verglichen. Dies diente einer besseren Vergleichbarkeit und der Interpretation nachfolgender Ergebnisse. Festzustellen war, dass die beiden Patientengruppen in einigen Punkten (Empfängeralter, WIZ, PRA-Werte, Einsatz von Tacrolimus und Ciclosporin) signifikante Unterschiede aufwiesen. PvNP-Patienten seit der Einführung des Screenings waren dabei mehr Risikofaktoren ausgesetzt: sie waren älter, vermehrt immunisiert (PRA) und bekamen häufiger Tacrolimus (und seltener Ciclosporin) als Immunsuppressivum. Diese Beobachtung muss bei der weiteren Interpretation der ScreeningEvaluation berücksichtigt werden.

In dem erfassten Beobachtungszeitraum konnte eine stetige Zunahme der Inzidenz bemerkt werden. Besonders deutlich war dies seit der Einführung des Screenings zu beobachten. Hier hatte sich die Inzidenz zum Vorjahreswert mehr als verdoppelt. Im Mittel betrug die jährliche 
Inzidenz 3,1\% im Zeitraum 2003 bis 2010, seit 2011 stieg sie durchschnittlich auf 12,5\%. Das Jahr 2014 weist sogar noch höhere Zahlen auf (19,4\%). Jedoch handelt es sich beim Letzteren nicht um ein absolut vermehrtes Vorkommen an PvNP-Fällen, sondern um insgesamt niedrigere Transplantationszahlen. Die DSO zeigt auch bundesweit seit 2012 bis 2017 einen rückläufigen Trend für Organtransplantationen (DSO 2018).

In der Literatur wird ebenfalls ein Anstieg der Inzidenz seit dem Ende der 1990er Jahre beschrieben, der mit einem vermehrten Einsatz von Immunsuppressiva einherging (Ramos et al. 2002a; Ramos et al. 2002b; Vasudev et al. 2005). Gerade bei Nierentransplantierten, die mit Tacrolimus behandelt werden, tritt eine PvNP häufiger auf als bei Patienten mit Ciclosporin (Brennan et al. 2005). Der protektive Effekt von Ciclosporin bezüglich der Entwicklung einer PvNP wird auf die Interaktion mit Cyclophilin A und eine damit verbundene Reduktion der BKV-Replikation zurückgeführt (Li et al. 2012). Dennoch gehört seit der Publikation der Symphony Studie 2009 die Kombinationstherapie aus low-dose Tacrolimus, MMF und Steroiden zur Standard-Immunsuppression nach Nierentransplantation. Denn für dieses Regime konnten bessere 1-Jahres- und 3-Jahres-Überlebensraten erzielt werden (Ekberg et al. 2009). Zentrumabhängig schwanken die Werte für Inzidenz zwischen 1-10\% (Hirsch et al. 2013), womit das NZN seit 2011 sogar höhere Werte erreicht. Fraglich ist an dieser Stelle, wie sich der starke Anstieg der Inzidenz begründen lässt. Sicherlich müssen mehrere Faktoren berücksichtigt werden: Durch das Screening und die Protokollbiopsie werden mehr Patienten erfasst und die Diagnose der PvNP früher gestellt, da gezielt danach gesucht wird. Gleichzeitig besteht die Gefahr, dass zuvor ohne das Screening die eigentliche Inzidenz unterschätzt wird. Möglicherweise spielt auch Tacrolimus als Immunsuppressivum hier eine Rolle. Denn auffällig war, dass bei PvNP-Patienten in dem Zeitraum 2011 bis 2014 im NZN signifikant häufiger Tacrolimus und seltener Ciclosporin angewandt wurde als in den Jahren zuvor, was als Risikofaktor für die Entwicklung einer PvNP diskutiert wird (Brennan et al. 2005; Li et al. 2012; Hirsch et al. 2013).

Außerdem konnte festgestellt werden, dass sich der Zeitpunkt der Erstdiagnose PvNP seit dem Einsatz des Screenings fast halbierte. Während er vorher im Mittel bei 13,3 Monaten lag, verkürzte er sich seit der Einführung des Screenings auf durchschnittlich 7,8 Monate nach der Transplantation. Auch die Streuung der Werte fiel geringer aus: 0-26,8 Monate (95\%-KI) ohne Screening im Vergleich zu 2-13,6 Monaten (95\%-KI) mit Screening. Die Entwicklung einer BKV-Reaktivierung bis hin zu der Diagnose einer PvNP wird in den meisten Publikationen am häufigsten innerhalb des ersten Jahren nach der Transplantation beobachtet (Hirsch et al. 2002; Ramos et al. 2002b; Vasudev et al. 2005; Prince et al. 2009; Park et al. 2018). Im NZN konnte die histologische Diagnose in einem ähnlichen Zeitraum gestellt werden, sowohl mit als auch ohne das Screeningverfahren. Dass durch Strategien der Früherkennung eine Diagnosestellung der PvNP in früheren Stadien oder bereits bei der BKV-Reaktivierung ermöglicht wird, lässt sich in der Literatur widerfinden (Buehrig et al. 2003; Dall und Hariharan 2008; Hirsch und Randhawa 2013). Eine frühere Diagnosestellung konnte auch im NZN durch das Screening erreicht werden. Ein Zusammenhang mit einer Verbesserung der Nierenfunktion 
zum Zeitpunkt der Erstdiagnose konnte allerdings nicht festgestellt werden. Eine kleine Senkung der durchschnittlichen Kreatininwerte von 2,65 mg/dl auf 2,38 mg/dl konnte mit der Einführung des Screenings beobachtet werden, für die jedoch keine Signifikanz nachweisbar war.

Die anschließende Untersuchung der Fragestellung, ob sich durch das veränderte Management im NZN ein Überlebensvorteil für PvNP-Patienten erkennen lässt, zeigte im Langzeitverlauf, vor allem ab drei Jahren nach der Transplantation, eine deutliche Tendenz zugunsten der gescreenten Gruppe, die bisher jedoch nicht signifikant war. Vor der Einführung des Screenings lebten 75\% der PvNP-Patienten bis zu 2,9 Jahren mit einem funktionierenden Transplantat. Seit der Einführung des Screenings verlängerte sich dieser Zeitraum auf 4,3 Jahre. Auch die 5-Jahres-Überlebensrate stieg von 64\% auf 71\%. Auch wenn bisher keine Signifikanz nachweisbar ist, scheinen PvNP-Patienten mit dem Screening ein besseres Outcome im Langzeitverlauf zu haben. Dies sollte vor allem vor dem Hintergrund, dass die Gruppe der PvNP-Patienten 2011 bis 2014 mehr mögliche Risikofaktoren aufwies (höheres Alter, höheres immunologisches Risiko, mehr Tacrolimus-Einsatz), hervorgehoben werden. In einer weiteren Analyse konnte außerdem eine Tendenz festgestellt werden, dass auch die Kontrollgruppe der Nierentransplantierten ohne eine PvNP von dem Screening profitieren. Das Langzeitüberleben stieg seit 2011, wenn auch nicht signifikant, an.

Bereits 2008 zeigte eine Studie, dass sich durch den Einsatz von Screeningverfahren und das zeitnahe Einleiten von Therapiemaßnahmen bessere Outcomes für PvNP-Patienten erreichen lassen (Dall und Hariharan 2008). Veröffentlichte Empfehlungen bezüglich des Einsatzes von Screeningverfahren sprechen davon, dass auf diese Weise 80-90\% der Risikopatienten für eine PvNP, noch bevor eine Funktionseinschränkung des Transplantats vorliegt, identifiziert werden können (Hirsch und Randhawa 2013). Die Kombination aus einem Screening auf Virämie und der frühzeitigen Reduktion der Immunsuppression kann das Fortschreiten und das Auftreten einer PvNP verhindern (Alméras et al. 2011). Ob oder welche Veränderungen sich dadurch möglicherweise für das Langzeitüberleben von PvNP-Patienten ergeben, lässt sich daraus nicht ableiten. Insgesamt gibt es kaum veröffentlichte Studien, die sich mit einer ähnlichen Fragestellung wie diese Arbeit befassen und mögliche Screeningverfahren hinsichtlich des Langzeitüberlebens von PvNP-Patienten auswerten. In einer Publikation von Moon et al. (2013) wurden zwei verschiedene Screeningprotokolle verglichen: Das erste basierte auf einer Urinuntersuchung und Quantifizierung der BKV-DNA, während beim zweiten später zusätzlich bei festgelegten Cut-Off-Werten eine Quantifizierung der Virämie sowie eine Biopsie erfolgten. Durch die Anwendung des zweiten Protokolls konnte eine Virämie früher diagnostiziert werden und es zeigte sich ein stärkerer Rückgang der BKV-Reaktivierung im Vergleich zum ersten Protokoll (Moon et al. 2013). Der Beobachtungszeitraum betrug jedoch nur zwölf Monate, weshalb auch hier keine Aussage bezüglich des Langzeitüberlebens gemacht werden kann. Eine andere monozentrische Studie evaluierte ein Screeningverfahren, bestehend aus einer quantitativen Bestimmung der BKV-DNA im Plasma sowie Protokoll- und Indikationsbiopsien. Im ersten Jahr nach der Transplantation wies die BKV-positive Gruppe (Virämie 
und/oder PvNP) eine signifikant schlechtere Nierenfunktion auf. Das Follow-Up über durchschnittlich vier Jahre zeigte jedoch keinen Unterschied im Langzeitüberleben von BKVpositiven und BKV-negativen Patienten (Simard-Meilleur et al. 2017). Diese Studie beschäftigt sich zwar mit dem Langzeitüberleben von Nierentransplantierten mit und ohne eine BKVInfektion, die ein Screening durchlaufen haben, sie kann aber keinen Vergleich zu nichtgescreenten Patienten ziehen.

Maßnahmen der Früherkennung sollen im Rahmen der Nachsorge von Nierentransplantierten dazu dienen, eine BKV-Infektion in einem möglichst frühen Stadium zu diagnostizieren und durch gezielte Behandlungsstrategien deren Fortschreiten sowie die Entwicklung einer chronischen Nephropathie zu verhindern. Im NZN konnte seit der Einführung des ScreeningProtokolls eine steigende Inzidenz, ein deutlich kürzerer Zeitraum zwischen der Transplantation und der Erstdiagnose PvNP sowie eine Tendenz zu einem besseren Langzeitüberleben von PvNP-Patienten beobachtet werden. Eine frühere Diagnosestellung und ein mögliches besseres Outcome können demnach durch das Screening auch im NZN erreicht werden. Eine Fortführung des Follow-Ups ist dennoch weiterhin wichtig, um einen längeren Zeitraum erfassen, eine bessere Aussage treffen und eventuell eine Signifikanz im Langzeitverlauf erzielen zu können.

Eine Analyse mittels des Kaplan-Meier-Schätzers ist nicht frei von möglichen Fehlern. Wie bei jeder Studie, die sich mit BKV und speziell mit der PvNP beschäftigt, stellt sich das Problem der geringen Fallzahl. Obwohl in dieser Studie mit 71 PvNP-Patienten eine vergleichsweise hohe Fallzahl erreicht wird, so stößt die Kaplan-Meier-Untersuchung dennoch auch an Grenzen. Die Unterteilung der 71 Patienten in zwei Gruppen sowie die Analyse von Ereignissen des Funktionsverlustes lassen die Zahl der Daten sinken. Als Ereignis wurde in der Untersuchung der Funktionsverlust des Transplantats festgelegt. Jedoch wurden auch Patienten, die während des Follow-Ups an einer anderen Ursache verstarben, ebenfalls als Funktionsverlust gewertet. Eine Beeinflussung des Ergebnisses ist dadurch nicht auszuschließen. Werden diese Patienten in der Untersuchung zensiert, so nähert sich das Ergebnis zwar der Signifikanzgrenze an, es gehen gleichzeitig jedoch auch weniger Daten in die Auswertung ein. Der bereits zuvor beschriebene immortal bias, eine Sonderform des selection bias, sollte hier ebenfalls nicht außer Acht gelassen werden. Das bedeutet für die Patienten im NZN, dass sie bis zur Diagnosestellung überlebt haben müssen, um in der Analyse aufzutauchen. Gescreente PvNPPatienten, bei denen beispielsweise die Diagnose im Rahmen der Protokollbiopsie drei oder zwölf Monate nach der Transplantation gestellt wurde, müssen entsprechend lange mit einem funktionierenden Transplantat gelebt haben. Dieser Einfluss könnte zu einem vorteilhafteren Verlauf für die Screening-Gruppe beitragen. Die Tendenz zu einem besseren Langzeitüberleben, die im NZN beobachtet werden kann, ist ein gutes Ergebnis. Dieses muss dennoch auch vor dem Hintergrund der limitierten Aussagefähigkeit sowie möglicher Fehlerquellen betrachtet werden. 


\subsubsection{Empfohlener Grenzwert zur Virämiebestimmung und die PvNP}

Werden Nierentransplantierte hinsichtlich einer BKV-Virämie gescreent, stellt sich die Frage, ab welcher Kopienzahl der BKV-DNA sich welche Konsequenzen für den Patienten ergeben, sei es eine wiederholte Messung, eine Biopsie oder eine Reduktion der immunsuppressiven Therapie. Aktuelle Empfehlungen der Banff Working Group geben vor, ab einem Wert von $\geq 10.000$ BKV-Kopien/ml die Diagnose einer vermutlichen PvNP stellen zu können, die durch eine Biopsie gesichert werden kann und eine Reduktion der Immunsuppression nach sich ziehen sollte (Nickeleit et al. 2018). Eine monozentrische Studie von Bicalho et al. (2018) untersuchte unter anderem, bei welchem Cut-Off eine Virämie am ehesten mit einer PvNP einher ging. Für dieses Zentrum wurden deutlich höhere Werte im Bereich von 40.000 BKVKopien/ml festgestellt (Bicalho et al. 2018). Eine andere monozentrische Studie hingegen kam zu dem Ergebnis, dass bei dem empfohlenen Cut-Off von 10.000 Kopien/ml ca. 35\% der PvNP-Patienten übersehen würden (Hassan et al. 2014). Die beiden zuletzt genannten Publikationen arbeiten mit einer kleinen Fallzahl und unterliegen den Limitationen von monozentrischen Studien, während sich die Empfehlungen der Banff Working Group auf Untersuchungen aus neun Transplantationszentren in den USA und in Europa stützen und eine der bisher größten systematischen Analysen für die PvNP darstellen.

Anhand der erhobenen Daten im NZN lässt sich keine ROC-Kurve erstellen, aus der sich der Cut-Off mit der besten Vorhersage für die Korrelation der Virämie mit der PvNP ableiten ließe. Hierfür fehlen ausreichende Daten der PCR-Analyse. Aus den PCR-Ergebnissen, die für die Studie vorliegen, kann dennoch beobachtet werden, dass insgesamt neun von 58 gesicherten PvNP-Fällen $(15,5 \%)$ Werte $<10.000 \mathrm{Kopien} / \mathrm{ml}$ aufweisen. Der empfohlene Grenzwert unterschätzt also die Häufigkeit der PvNP im NZN.

\subsection{Allgemeine Diskussion, Limitationen der Arbeit und Ausblick}

Bei dieser Arbeit handelt es sich um eine retrospektive monozentrische Studie. Zunächst einmal unterliegt sie allgemeinen Limitationen von retrospektiven Studien. Die Daten wurden rückwirkend erhoben und erlauben nur die Erstellung von Hypothesen. Es kann daraus kein Kausalzusammenhang geschlossen werden. Auch die statistischen Methoden können in dem Rahmen nur eine Richtung vorgeben, aber keine Kausalität erklären. Confounder können auf diese Weise nicht ausgeschlossen werden. Beispielsweise zeigt die Kaplan-MeierUntersuchung von PvNP-Patienten, dass seit dem Einsatz des Screeningverfahrens die gescreente Gruppe tendenziell ein besseres Langzeitüberleben erreicht. Daraus kann nicht geschlussfolgert werden, ob das Screeningverfahren für den Zusammenhang allein ursächlich ist oder ob weitere Faktoren, wie allgemeine Verbesserungen in der Versorgung von Nierentransplantierten, das Ergebnis mitbeeinflussen. Andererseits stellt der retrospektive Charakter der Studie auch einen Vorteil dar. Durch die Erhebung der Daten können ein vergleichsweise langer Zeitraum und eine große Menge an Patienten erfasst werden. Gerade im Hinblick auf die geringe Zahl der jährlich Nierentransplantierten und eine noch geringere Fallzahl an 
PvNP-Patienten können so deutlich mehr Daten erhoben werden, als dies im Rahmen einer prospektiven Studie möglich wäre. Da es sich um eine monozentrische Studie handelt, kann von einem tendenziell einheitlichen Management in der Nachsorge von Nierentransplantierten ausgegangen werden, mit den Unterschieden vor und nach der Einführung des Screeningverfahrens. Da aber in der Evaluation des Screenings PvNP-Patienten entsprechend in zwei Gruppen einander gegenübergestellt werden, stellt sich dadurch kein Bias ein. Die Ergebnisse müssen dennoch für das Zentrum spezifisch betrachtet werden und können keine Allgemeingültigkeit aussprechen. Dafür sollten weitere Studien mit einer ähnlichen Fragestellung an anderen Transplantationszentren unter standardisierten Bedingungen durchgeführt werden. Denn, gerade weil es keine allgemeinen Standards im Umgang mit der BKV-Infektion gibt, kann die Variabilität zwischen einzelnen Zentren groß sein.

Wie bei allen Studien, die sich mit dem BK-Virus beschäftigen, stellt sich auch hier das Problem einer geringen Fallzahl. Obwohl eine Seropositivität bei einem Großteil der Allgemeinbevölkerung vorliegt, betrifft eine PvNP nur 1-10\% der Nierentransplantierten, die per se bereits eine kleine Bevölkerungsgruppe darstellen. Hinzu kommt die Schwierigkeit der Diagnosestellung einer PvNP: Es handelt sich um eine Nephropathie mit fokalem Befall, die nur histologisch bestätigt werden kann. Durch den fokalen Charakter kann jedoch bei einer negativen Biopsie eine PvNP nicht ausgeschlossen werden. Unter diesen Voraussetzungen stellt diese Arbeit, die mit 71 bioptisch gesicherten PvNP-Fällen eine verhältnismäßig hohe Fallzahl erreicht, eine Besonderheit dar. Der erfasste Zeitraum, der durch die Veränderung des Managements hinsichtlich der BKV-Infektion einen Vergleich von vorher und danach erlaubt, ist bei der aktuellen Studienlage ebenfalls einzigartig. Im Hinblick auf die zu Beginn gestellten Hypothesen können aus den Ergebnissen der Studie für das NZN folgende Schlussfolgerungen gezogen werden:

1. Die gewählte Kohorte der Studie deckt sich mit Nierentransplantierten anderer Zentren. Dies wird durch die demographischen Daten und die Risikofaktorenanalyse deutlich.

2. Das männliche Geschlecht des Empfängers und eine erhöhte Immunsuppression durch den Einsatz von Tacrolimus sind mit einem vermehrten Vorkommen an PvNP assoziiert.

3. Eine PvNP kann im NZN entgegen der Literatur nicht eindeutig als Risikofaktor für das Transplantatüberleben identifiziert werden. Die Untersuchung unterliegt jedoch einigen Bias, die den Verlauf beeinflussen.

4. Der Einsatz des Screeningverfahrens bringt einen Nutzen für PvNP-Patienten. Seit der Einführung kann eine erhöhte Inzidenz, ein früherer Zeitpunkt der Erstdiagnose sowie die Tendenz eines besseren Outcomes für PvNP-Patienten, trotz vermehrter Risiken (höheres Alter, stärkere Immunisierung, vermehrter Tacrolimus-Einsatz), beobachtet werden.

5. Durch die Anwendung des Screeningverfahrens mit dem empfohlenen Cut-Off von 10.000 Kopien/ml in der PCR würden im NZN 15,5\% der PvNP-Patienten übersehen werden. 
Eine Fortsetzung der Follow-Up-Untersuchung ist weiterhin notwendig, da die allermeisten Veröffentlichungen sich mit einem Beobachtungszeitraum von ein bis zwei Jahren befassen. Dadurch fehlt es an Daten zum Langzeitüberleben. Die PvNP ist jedoch eine chronische Erkrankung, die über mehrere Jahre verlaufen kann. Deswegen ist es wichtig, den Langzeitverlauf zu untersuchen und bei der Evaluation von Screeningverfahren zu berücksichtigen. Da sich die Schlussfolgerungen zunächst auf das NZN beziehen lassen, sollte hinsichtlich des Screenings mittels der PCR im Serum der empfohlene Grenzwert von $10.000 \mathrm{Kopien} / \mathrm{ml}$ an weiteren Transplantationszentren überprüft werden. Ebenfalls wären Studien an weiteren Zentren wichtig, um größere Fallzahlen zu generieren und die erstellten Hypothesen bestätigen oder widerlegen zu können. Dem können sich dann prospektive Studien anschließen. 


\section{$5 \quad$ Zusammenfassung}

\section{Einleitung:}

Die Nierentransplantation stellt die Therapie der Wahl bei terminalem Nierenversagen dar. Nach der Transplantation werden Immunsuppressiva eingesetzt, um unter anderem das Auftreten akuter und chronischer Abstoßungsreaktionen zu vermindern. Gleichzeitig birgt der Einsatz auch die Gefahr einer erhöhten Infektanfälligkeit. So kann eine Infektion mit dem BK-Virus bis zu einer chronischen Polyomavirus-Nephropathie fortschreiten und das Organüberleben gefährden. $\mathrm{BKV}$ und die $\mathrm{PvNP}$ stellen dabei ein verhältnismäßig junges Forschungsfeld dar mit nur wenigen Untersuchungen zum Langzeitüberleben betroffener Patienten. Obwohl das Virus in der Allgemeinbevölkerung sehr weit verbreitet ist, wird das Krankheitsbild einer PvNP nur selten und nur bei Nierentransplantierten beobachtet. Außerdem fehlen nach wie vor spezifische antivirale Therapien. Stattdessen wird der Einsatz von Screeningverfahren und eine Reduktion der immunsuppressiven Therapie empfohlen. Auf der Grundlage dieser Problemfelder entstand die vorliegende Arbeit.

\section{Methoden:}

Für die retrospektive monozentrische Studie wurden im NZN/Klinikum Hann. Münden die Daten aller nierentransplantierter Patienten im Zeitraum 2003 bis 2014 erhoben. Von den erfassten 1222 Nierentransplantierten entwickelten im Verlauf 71 Patienten eine histologisch gesicherte PvNP. Mit Beginn des Jahres 2011 wurde im NZN ein Screeningverfahren eingeführt, welches eine regelmäßige Viruslastbestimmung mittels BKV-PCR im Serum sowie eine zusätzliche Protokollbiopsie drei und zwölf Monate nach der Transplantation beinhaltete. Anhand der erhobenen Daten wurde zunächst eine Risikofaktorenanalyse der PvNP durchgeführt und untersucht, welche Auswirkungen eine PvNP auf das Transplantatüberleben hat. Im Anschluss wurde das Screeningverfahren evaluiert. Vordergründig waren hierfür Veränderungen der Inzidenz, des Zeitpunktes der Erstdiagnose und des Langzeitüberlebens von PvNPPatienten. Außerdem konnten die PCR-Ergebnisse für PvNP-Patienten bezogen auf den empfohlenen Cut-Off von $10.000 \mathrm{Kopien} / \mathrm{ml}$ ausgewertet werden.

\section{Ergebnisse:}

In der Analyse möglicher Risikofaktoren konnten das männliche Geschlecht des Empfängers und eine erhöhte Immunsuppression durch den Einsatz von Tacrolimus mit einem vermehrten Vorkommen an PvNP-Fällen assoziiert werden. Dass eine PvNP die Nierenfunktion und das Transplantatüberleben negativ beeinflussen kann, konnte in der Kaplan-MeierUntersuchung für das NZN nicht eindeutig nachgewiesen werden. 
Durch den Einsatz des Screeningverfahrens konnte ein gewisser Nutzen für PvNP-Patienten festgestellt werden: Seit der Einführung erhöhte sich die Inzidenz, die Erstdiagnose der PvNP konnte früher gestellt werden und es zeigte sich die Tendenz eines besseren Outcomes zugunsten der gescreenten Gruppe trotz vermehrter Risiken (höheres Alter, stärkere Immunisierung, vermehrter Tacrolimus-Einsatz). Die Untersuchung des empfohlenen Cut-Off-Wertes für die Anwendung der BKV-PCR im Serum als Screeningverfahren brachte hervor, dass bei einem Grenzwert von 10.000 Kopien/ml im NZN 15,5\% der PvNP-Patienten nicht erfasst werden würden.

\section{Diskussion:}

Die vorliegende Arbeit weist einige Besonderheiten auf: Durch den retrospektiven Charakter der Studie konnte eine große Zahl nierentransplantierter Patienten mit einer vergleichsweise großen Fallzahl an histologisch gesicherten PvNP-Fällen erfasst werden. Der lange Zeitraum bietet darüber hinaus die Möglichkeit, die Patienten vor und nach der Einführung des Screenings miteinander zu vergleichen. Außerdem ist der Beobachtungszeitraum der Follow-UpUntersuchung mit mindestens 3,5 Jahren einzigartig und erlaubt Aussagen zum Langzeitüberleben von PvNP-Patienten.

Gleichzeitig unterliegt die Arbeit allgemeinen Limitationen von retrospektiven monozentrischen Studien und einigen Bias, die sich aus der statistischen Auswertung ergeben (z. B. unterschiedliche Gruppengrößen, selection bias). Anhand der Ergebnisse können nur Hypothesen erstellt werden, die nicht per se auf einen Kausalzusammenhang schließen. Auch müssen die Ergebnisse zunächst einmal zentrumspezifisch betrachtet werden und können keine Allgemeingültigkeit aussprechen. Dafür sollten weitere Studien an anderen Transplantationszentren unter standardisierten Bedingungen folgen. Im Anschluss wären prospektive Studien sinnvoll, um die erstellten Hypothesen bestätigen oder widerlegen zu können. 


\section{$6 \quad$ Literaturverzeichnis}

Alméras C, Vetromile F, Garrigue V, Szwarc I, Foulongne V, Mourad G (2011): Monthly screening for BK viremia is an effective strategy to prevent BK virus nephropathy in renal transplant recipients. Transpl Infect Dis $\underline{13}, 101-108$

Bicalho CS, Oliveira R dos R, David DR, Fink MCDS, Agena F, Castro MC, Panutti C, David-Neto E, Pierrotti LC (2018): Determination of viremia cut-off for risk to develop BKPyV-associated nephropathy among kidney transplant recipients. Transpl Infect Dis 20, e12969

Binet I, Nickeleit V, Hirsch HH, Prince O, Dalquen P, Gudat F, Mihatsch MJ, Thiel G (1999): Polyomavirus disease under new immunosuppressive drugs: a cause of renal graft dysfunction and graft loss. Transplantation $\underline{67}, 918-922$

Bohl DL, Brennan DC (2007): BK Virus Nephropathy and Kidney Transplantation. Clin J Am Soc Nephrol 2, S36-S46

Brennan DC, Agha I, Bohl DL, Schnitzler MA, Hardinger KL, Lockwood M, Torrence S, Schuessler R, Roby T, Gaudreault-Keener M, et. al. (2005): Incidence of BK with Tacrolimus Versus Cyclosporine and Impact of Preemptive Immunosuppression Reduction. Am J Transplant $\underline{5}$, 582-594

Buehrig CK, Lager DJ, Stegall MD, Kreps MA, Kremers WK, Gloor JM, Schwab TR, Velosa JA, Fidler ME, Larson TS, et. al. (2003): Influence of surveillance renal allograft biopsy on diagnosis and prognosis of polyomavirus-associated nephropathy. Kidney Int $\underline{64}$, 665-673

Cubitt CL, Stoner GL (2006): Molecular Genetics of the BK Virus. Adv Exp Med Biol 577, 85-95

Dall A, Hariharan S (2008): BK Virus Nephritis after Renal Transplantation. Clin J Am Soc Nephrol $\underline{3}$, S68-S75

Davison SN, Jhangri GS (2010): Impact of Pain and Symptom Burden on the HealthRelated Quality of Life of Hemodialysis Patients. J Pain Symptom Manage 39, 477-485

Drachenberg CB, Papadimitriou JC, Wali R, Cubitt CL, Ramos E (2003): BK Polyoma Virus Allograft Nephropathy: Ultrastructural Features from Viral Cell Entry to Lysis. Am J Transplant $\underline{3}, 1383-1392$

Drachenberg CB, Papadimitriou JC, Hirsch HH, Wali R, Crowder C, Nogueira J, Cangro CB, Mendley S, Mian A, Ramos E (2004a): Histological Patterns of Polyomavirus Nephropathy: Correlation with Graft Outcome and Viral Load. Am J Transplant $\underline{4}$, 2082-2092

Drachenberg CB, Papadimitriou JC, Wali R, Nogueira J, Mendley S, Hirsch HH, Cangro CB, Klassen DK, Weir MR, Bartlett ST, et al. (2004b): Improved outcome of polyoma virus allograft nephropathy with early biopsy. Transplant Proc $\underline{36}, 758-759$ 
DSO Jahresbericht 2017 - Organspende und Transplantation in Deutschland. Deutsche Stiftung Organtransplantation, Frankfurt a. M. 2018.

https://www.dso.de/servicecenter/downloads/jahresberichte-und-grafiken.html; abgerufen am 24.10.2018

Egli A, Binggeli S, Bodaghi S, Dumoulin A, Funk GA, Khanna N, Leuenberger D, Gosert R, Hirsch HH (2007): Cytomegalovirus and polyomavirus BK posttransplant. Nephrol Dial Transplant 22, viii72-viii82

Ekberg H, Bernasconi C, Tedesco-Silva H, Vítko S, Hugo C, Demirbas A, Acevedo RR, Grinyó J, Frei U, Vanrenterghem Y, et al. (2009): Calcineurin inhibitor minimization in the Symphony study: observational results 3 years after transplantation. Am J Transplant $\underline{9}, 1876-1885$

Emami A, Yaghobi R, Moattari A, Salehi MB, Roozbeh J (2017): Noncoding Control Region Pattern of BK Polyomavirus in Kidney Transplant Patients With Nephropathy. Exp Clin Transplant $\underline{15}, 150-156$

ERA-EDTA Registry Annual Report 2016. ERA-EDTA Registry, Amsterdam 2018. https://www.era-edta-reg.org/files/annualreports/pdf/AnnRep2016.pdf; abgerufen am 04.12.2018

Frei U, Schober-Halstenberg H-J: Nierenersatztherapie in Deutschland - Bericht über Dialysebehandlung und Nierentransplantation in Deutschland, 2006-2007. QuaSi-Niere gGmbH, Berlin 2008. http://www.bundesverband-

niere.de/fileadmin/user_upload/QuaSi-Niere-Bericht_2006-2007.pdf; abgerufen am 23.08.2018

Gardner SD (1973): Prevalence in England of antibody to human polyomavirus (B.k.). Br Med J $1,77-78$

Gardner SD, Field AM, Coleman DV, Hulme B (1971): New human papovavirus (B.K.) isolated from urine after renal transplantation. Lancet $\underline{1}, 1253-1257$

Gardner SD, MacKenzie EF, Smith C, Porter AA (1984): Prospective study of the human polyomaviruses BK and JC and cytomegalovirus in renal transplant recipients. $\mathrm{J}$ Clin Pathol $\underline{37}, 578-586$

Goudsmit J, Dillen PW, van Strien A, van der Noordaa J (1982): The role of BK virus in acute respiratory tract disease and the presence of BKV DNA in tonsils. J Med Virol $\underline{10}, 91-99$

Gouvêa ALF, Cosendey RIJ, Carvalho FR, Varella RB, de Souza CF, Lopes PF, Silva AA, Rochael MC, de Moraes HP, Lugon JR, et. al. (2016): Pilot Study of Early Monitoring Using Urinary Screening for BK Polyomavirus as a Strategy for Prevention of BKV Nephropathy in Kidney Transplantation. Transplant Proc 48, 2310-2314

Hariharan S, Johnson CP, Bresnahan BA, Taranto SE, McIntosh MJ, Stablein D (2000): Improved graft survival after renal transplantation in the United States, 1988 to 1996. N Engl J Med 342, 605-612

Haririan A, Klassen DK (2002): BK Virus Infection after Nonrenal Transplantation. Graft $\underline{5}, \mathrm{~S} 58-\mathrm{S} 64$ 
Hassan S, Mittal C, Amer S, Khalid F, Patel A, Delbusto R, Samuel L, Alangaden G, Ramesh M (2014): Currently recommended BK virus (BKV) plasma viral load cutoff of $\geq 4 \log 10 / \mathrm{mL}$ underestimates the diagnosis of BKV-associated nephropathy: a single transplant center experience. Transpl Infect Dis 16, 55-60

Hirsch HH (2002): Polyomavirus BK Nephropathy: A (Re-)emerging Complication in Renal Transplantation. Am J Transplant $\underline{2}, 25-30$

Hirsch HH, Randhawa P (2013): BK Polyomavirus in Solid Organ Transplantation. Am J Transplant $\underline{13}, 179-188$

Hirsch HH, Knowles W, Dickenmann M, Passweg J, Klimkait T, Mihatsch MJ, Steiger J (2002): Prospective Study of Polyomavirus Type BK Replication and Nephropathy in Renal-Transplant Recipients. N Engl J Med 347, 488-496

Hirsch HH, Vincenti F, Friman S, Tuncer M, Citterio F, Wiecek A, Scheuermann EH, Klinger M, Russ G, Pescovitz MD, et. al. (2013): Polyomavirus BK Replication in De Novo Kidney Transplant Patients Receiving Tacrolimus or Cyclosporine: A Prospective, Randomized, Multicenter Study: Risk Factors of BKV in Kidney Transplantation. Am J Transplant $\underline{13}$, 136-145

Hogan TF, Borden EC, McBain JA, Padgett BL, Walker DL (1980): Human polyomavirus infections with JC virus and BK virus in renal transplant patients. Ann Intern Med $\underline{92}, 373-378$

Knowles WA: The Epidemiology of BK Virus and the Occurrence of Antigenic and Genomic Subtypes. In: Khalili K, Stoner GL (Hrsg.): Human Polyomaviruses. John Wiley \& Sons, New York 2001, 527-559

Li R-M, Mannon RB, Kleiner D, Tsokos M, Bynum M, Kirk AD, Kopp JB (2002): BK virus and SV40 co-infection in polyomavirus nephropathy. Transplantation $\underline{74}$, $1497-1504$

Li YJ, Wu HH, Weng CH, Chen YC, Hung CC, Yang CW, Wang RYL, Sakamoto N, Tian YC (2012): Cyclophilin A and Nuclear Factor of Activated T Cells Are Essential in Cyclosporine-Mediated Suppression of Polyomavirus BK Replication: Cyclosporine Inhibits BKV via CypA and NFAT. Am J Transplant 12, 2348-2362

Mackenzie EF, Poulding JM, Harrison PR, Amer B (1978): Human polyoma virus (HPV)-a significant pathogen in renal transplantation. Proc Eur Dial Transplant Assoc 15, $352-360$

Maldonado AQ, Asempa T, Hudson S, Rebellato LM (2017): Prevalence of CYP3A5 Genomic Variances and Their Impact on Tacrolimus Dosing Requirements among Kidney Transplant Recipients in Eastern North Carolina. Pharmacotherapy $\underline{37}$, $1081-1088$

Moens U, Rekvig OP: Molecular Biology of BK Virus and Clinical and Basic Aspects of BK Virus Renal Infection. In: Khalili K, Stoner GL (Hrsg.): Human Polyomaviruses. John Wiley \& Sons, New York 2001, 359-408 
Moon HH, Kim T-S, Lee S, Song S, Shin M, Park JB, Kim JM, Kwon CHD, Joh J-W, Lee S-K, et. al. (2013): Monitoring and treatment for BK virus after kidney transplantation. Transplant Proc 45, 2980-2983

Moulin B, Merville P, Renaudin K, Buob D, Ferlicot S, Delahousse M, Dantal J, Albano L, Barbet C, Mourad G, et. al. (2012): Evaluation of Protocol Biopsy Utility 12 Months after Renal Transplantation: A Multicenter Observational Analysis. J Transplant 2012, 781263

Nankivell BJ, Renthawa J, Sharma RN, Kable K, O’Connell PJ, Chapman JR (2017): BK Virus Nephropathy: Histological Evolution by Sequential Pathology. Am J Transplant $\underline{17}, 2065-2077$

Nickeleit V, Hirsch HH, Binet IF, Gudat F, Prince O, Dalquen P, Thiel G, Mihatsch MJ (1999): Polyomavirus Infection of Renal Allograft Recipients: From Latent Infection to Manifest Disease. J Am Soc Nephrol 10, 1080-1089

Nickeleit V, Klimkait T, Binet IF, Dalquen P, Del Zenero V, Thiel G, Mihatsch MJ, Hirsch HH (2000): Testing for Polyomavirus Type BK DNA in Plasma to Identify RenalAllograft Recipients with Viral Nephropathy. N Engl J Med 342, 1309-1315

Nickeleit V, Singh HK, Randhawa P, Drachenberg CB, Bhatnagar R, Bracamonte E, Chang A, Chon WJ, Dadhania D, Davis VG, et al. (2018): The Banff Working Group Classification of Definitive Polyomavirus Nephropathy: Morphologic Definitions and Clinical Correlations. J Am Soc Nephrol 29, 680-693

Nicoletto BB, Fonseca NKO, Manfro RC, Gonçalves LFS, Leitão CB, Souza GC (2014): Effects of Obesity on Kidney Transplantation Outcomes: A Systematic Review and Meta-Analysis. Transplantation $\underline{98}, 167-176$

Ozkul F, Erbis H, Yilmaz VT, Kocak H, Osmanoglu IA, Dinckan A (2016): Effect of age on the outcome of renal transplantation: A single-center experience. Pac J Med Sci $\underline{32}, 827-830$

Padgett BL, Walker DL, ZuRhein GM, Hodach AE, Chou SM (1976): JC Papovavirus in Progressive Multifocal Leukoencephalopathy. J Infect Dis 133, 686-690

Park WY, Kang SS, Jin K, Park SB, Choe M, Han S (2018): Long-term prognosis of BK virus-associated nephropathy in kidney transplant recipients. Kidney Res Clin Pract $\underline{37}, 167-173$

Pinto GG, Poloni JAT, Rotta LN, Razonable RR, Pasqualotto AC (2016): Screening for BK virus nephropathy in kidney transplant recipients: comparison of diagnostic tests. J Bras Nefrol $\underline{38}, 356-362$

Polo C, Pérez JL, Mielnichuck A, Fedele CG, Niubo J, Tenorio A (2004): Prevalence and patterns of polyomavirus urinary excretion in immunocompetent adults and children. Clin Microbiol Infect 10, 640-644

Polyomaviridae Study Group of the ICTV, Calvignac-Spencer S, Feltkamp MCW, Daugherty MD, Moens U, Ramqvist T, Johne R, Ehlers B (2016): A taxonomy update for the family Polyomaviridae. Arch Virol 161, 1739-1750 
Potthoff F, Münscher C, Berendes A, Weber W: Jahresbericht 2016 zur Qualität in der Dialyse. Medical Netcare GmbH, Gemeinsamer Bundesausschuss, Berlin 2017. https://m-nc.de/qs-dialyse; abgerufen am 04.12.2018

Prince O, Savic S, Dickenmann M, Steiger J, Bubendorf L, Mihatsch MJ (2009): Risk factors for polyoma virus nephropathy. Nephrol Dial Transplant 24, 1024-1033

Ramos E, Drachenberg CB, Portocarrero M, Wali R, Klassen DK, Fink JC, Farney A, Hirsch H, Papadimitriou JC, Cangro CB, et al. (2002a): BK virus nephropathy diagnosis and treatment: experience at the University of Maryland Renal Transplant Program. Clin Transpl 143-153

Ramos E, Drachenberg CB, Papadimitriou JC, Hamze O, Fink JC, Klassen DK, Drachenberg RC, Wiland A, Wali R, Cangro CB, et al. (2002b): Clinical Course of Polyoma Virus Nephropathy in 67 Renal Transplant Patients. J Am Soc Nephrol $\underline{13}, 2145-2151$

Randhawa PS, Finkelstein S, Scantlebury V, Shapiro R, Vivas C, Jordan M, Picken MM, Demetris AJ (1999): Human polyoma virus-associated interstitial nephritis in the allograft kidney. Transplantation 67, 103-109

Sar A, Worawichawong S, Benediktsson H, Zhang J, Yilmaz S, Trpkov K (2011): Interobserver agreement for Polyomavirus nephropathy grading in renal allografts using the working proposal from the 10th Banff Conference on Allograft Pathology. Hum Pathol $\underline{42}$, 2018-2024

Sawinski D, Goral S (2015): BK virus infection: an update on diagnosis and treatment. Nephrol Dial Transplant $\underline{30}$, 209-217

Scadden JR, Sharif A, Skordilis K, Borrows R (2017): Polyoma virus nephropathy in kidney transplantation. World J Transplant $\underline{7}, 329-338$

Schold JD, Rehman S, Kayler LK, Magliocca J, Srinivas TR, Meier-Kriesche H-U (2009): Treatment for BK virus: incidence, risk factors and outcomes for kidney transplant recipients in the United States. Transpl Int 22, 626-634

Schulz K-H, Thaiss F (2012): Langzeitüberleben bei chronischer Niereninsuffizienz. Bundesgesundheitsblatt Gesundheitsforschung Gesundheitsschutz 55, 543-551

Seif I, Khoury G, Dhar R (1979): The genome of human papovavirus BKV. Cell $\underline{18}$, $963-$ 977

Seo CH, Ju JI, Kim M-H, Jun KW, Ahn S-H, Hwang JK, Kim SD, Park SC, Choi BS, Kim JI, et al. (2015): Risk factors and long-term outcomes of delayed graft function in

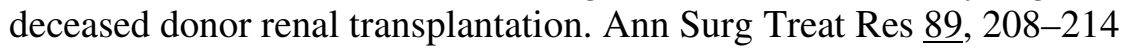

Sharma R, Tzetzo S, Patel S, Zachariah M, Sharma S, Melendy T (2016): BK Virus in Kidney Transplant: Current Concepts, Recent Advances, and Future Directions. Exp Clin Transplant $\underline{14}, 377-384$

Simard-Meilleur M-C, Bodson-Clermont P, St-Louis G, Pâquet MR, Girardin C, Fortin MC, Cardinal H, Hébert M-J, Lévesque R, Renoult E (2017): Stabilization of renal function after the first year of follow-up in kidney transplant recipients treated for 
significant BK polyomavirus infection or BK polyomavirus-associated nephropathy. Transpl Infect Dis $\underline{19}$

Sis B, Mengel M, Haas M, Colvin RB, Halloran PF, Racusen LC, Solez K, Baldwin WM, Bracamonte ER, Broecker V, et al. (2010): Banff '09 Meeting Report: Antibody Mediated Graft Deterioration and Implementation of Banff Working Groups. Am J Transplant 10, 464-471

Trnka P, McTaggart SJ, Francis A (2018): The impact of donor/recipient age difference and HLA mismatch on graft outcome in pediatric kidney transplantation. Pediatr Transplant 22, e13265

Vasudev B, Hariharan S, Hussain SA, Zhu Y-R, Bresnahan BA, Cohen EP (2005): BK virus nephritis: Risk factors, timing, and outcome in renal transplant recipients. Kidney Int $\underline{68}, 1834-1839$

Wiseman AC (2009): Polyomavirus nephropathy: a current perspective and clinical considerations. Am J Kidney Dis 54, 131-142 


\section{Danksagung}

Ich möchte mich an dieser Stelle bei einigen Menschen bedanken, ohne die diese Arbeit nicht zustande gekommen wäre: Ein Dank geht an Dr. med. P. Weithofer, durch den die Idee, die Zusammenarbeit mit dem NZN und die Erhebung der Daten ermöglicht wurde. Er stand mir jederzeit mit Rat und Tat zur Seite. Prof. Dr. O. Gross und Priv.-Doz. Dr. T. Lorf unterstützten mich ebenfalls mit kritischen Fragen und Anregungen während dieser Zeit. Vielen Dank dafür. Ein weiterer Dank geht an die Mitarbeiter*innen der biomedizinischen Statistik der Georg-August-Universität, die immer ein offenes Ohr für Fragen hatten. Zu guter Letzt möchte ich mich bei Dr. P. Geißler sowie allen Mitarbeiter*innen der Abteilung Studienförderung der Hans-Böckler-Stiftung für die jahrelange Unterstützung auf meinem Weg im Studium und bei dieser Promotion bedanken! 